\title{
PULMONARY HYPERTENSION IN CONGENITAL HEART DISEASE
}

\author{
BY \\ WILLIAM EVANS and D. S. SHORT \\ From the Cardiac Department of the London Hospital
}

Received February 10, 1958

An important group of congenital cardiovascular defects is that characterized by the presence of an arterio-venous shunt, of which atrial septal defect, ventricular septal defect, and patent ductus arteriosus are common examples. In these the flow of blood is generally directed from left to right so that cyanosis is absent, but some may ultimately develop cyanosis (cyanose tardive) following a reversal of the shunt. Cardiac catheterization may then show the pressure in the pulmonary artery to be raised to the same level as that in the aorta.

Ligature of a patent ductus is a safe procedure and the surgical treatment of atrial and ventricular septal defect is becoming established practice. The need now is to recognize in these cases the advent of pulmonary hypertension due to obstructive pulmonary vascular disease, for closure of the fistula in this circumstance cannot be curative.

Although close attention has been paid to the pathology of pulmonary hypertension associated with congenital heart disease in recent years, there is need for further investigation into the mechanism of the hypertension, and a readier recognition of the particular congenital lesion associated with it. In previous papers we described pulmonary hypertension as a solitary finding (Evans et al., 1957), and again in association with mitral stenosis (Evans and Short, 1957). In this paper we deal with it in conjunction with congenital cardiovascular disease. Although such a combination is not rare in clinical practice, we have elected to describe here only the 11 cases that were ultimately examined at necropsy.

As in our two previous series of patients a diagnosis of pulmonary hypertension was made from a clinical, electrocardiographic, and radiological examination, and independent of cardiac catheterization which was carried out in some of the patients. Thus, we have defined pulmonary hypertension as a persistent rise of pulmonary arterial pressure sufficient to cause enlargement and ultimately failure of the right ventricle, with characteristic clinical, electrocardiographic and radiological signs. A perusal of the growing number of reports of pulmonary hypertension has convinced us of the need to adhere to this definition. The acceptance of pulmonary arterial pressure readings as the sole arbiter of pulmonary hypertension, irrespective of evidence of right ventricular hypertrophy, will lead inevitably to the confusion now commonplace in the diagnosis of systemic hypertension when deduced exclusively from manometric readings from the arm. In cases of congenital heart disease with left-to-right shunt the pulmonary arterial pressure is frequently raised, but in only a proportion of these is there true pulmonary hypertension. This distinction is imperative for the proper management of the patients.

The 11 cases that we describe are arranged in four groups according to the kind of congenital anomaly found in association with pulmonary hypertension. Thus, there were three patients with atrial septal defect, three with ventricular septal defect, four with patent ductus arteriosus, and one with a common aorto-pulmonary trunk. Pulmonary arteriography was carried out at necropsy in four of the cases. In the others the test could not be performed because the patient had died suddenly either at home or at another hospital. Blocks were taken for histological examination in every 
case. In Case 10, only two blocks were made available, but in the others between 4 and 18 blocks were removed. These were examined after staining with either Hart or Verhoeff elastic stain.

In the sections that follow we first present the clinical and pathological findings in each patient, and subsequently the effects that pulmonary hypertension and the particular congenital anomaly may have on one another. Finally, we consider the pathology and pathogenesis of the hypertension in relation to the congenital cardiovascular defects as a group.

\section{Pulmonary Hypertension in Atrial Septal Defect Case Reports}

Glossary of Abbreviations: $\mathrm{BP}=\mathrm{Blood}$ pressure. $\mathrm{MCL}=\mathrm{Mid}$-clavicular line. $\mathrm{AAL}=$ Anterior axillary line. SVC $=$ Superior vena cava. $R A=$ Right atrium. $R V=$ Right ventricle. $L V=$ Left ventricle. LA=Left atrium. PA = Pulmonary artery. RUL and RLL=Right upper and lower lobes. LUL and LLL=Left upper and lower lobes. $\mathrm{EC}=$ Electrocardiogram. $\mathrm{PAP}=$ Pulmonary artery pressure. $\mathrm{PCP}=$ Pulmonary capillary pressure. $\mathrm{RBC}=$ Red blood cells in millions per c. mm. WBC $=$ White blood cells in thousands per c. mm. Hb=Hæmoglobin expressed as percentage. $\mathrm{WR}=$ Wassermann reaction. $\mathrm{Wt}=$ Weight. $\mathrm{FOC}=$ Foramen ovale closed. $\mathrm{FOP}=$ Foramen ovale patent.

Case 1. S. S., aged 52, a married woman without children. No symptoms until 36, when she started attacks of paroxysmal tachycardia. At the age of 49 one attack lasted a fortnight, and she was admitted to hospital with congestive heart failure.

Examination. During the paroxysm, the patient was dyspnœic and cyanosed, with jugular venous engorgement and slight odema. BP 120/80. After sinus rhythm had been restored she remained cyanosed. No clubbing of fingers. The apex beat was just outside the MCL, and there was a systolic thrill and murmur. A single second sound was followed by a Graham Steell murmur. RBC, 6.64. Hb, 126. Arterial oxygen, 67\%.

Radiology. Great enlargement of RA and of PA which bulged. PA branches dilated and abnormally pulsatile. Clear peripheral lung fields. Pulmonary hilar clouding latterly.

$E C$. At different times the tracing showed normal rhythm, extrasystoles, auricular tachycardia, auricular fibrillation, and auricular standstill. $S$ wave deep in I and CR7, and absent in CR1 where $R$ was very tall. $T$ wave inverted in leads II, III, and in CR1 to CR4. P wave diphasic in CR1. Partial right bundle-branch block pattern.

Course. Progressive dyspnœa on effort and odema of the ankles. A year later she had two pulmonary emboli in quick succession and died suddenly.

Necropsy. Customary changes of heart failure in viscera. No thrombosis in heart or in pelvic or femoral veins.

Heart. Wt $650 \mathrm{~g}$. Great dilatation and hypertrophy of RA and RV $(0.9 \mathrm{~cm}$. thick). LV normal $(1 \cdot 1 \mathrm{~cm}$. thick). Slight thickening of aortic cusp of mitral valve. Defect $(3 \mathrm{~cm}$. diam.) in posterior part of atrial septum.

Lungs. Recent hæmorrhagic infarcts of right middle and lower lobes. PA trunk, right, left, and segmental branches dilated and bearing numerous flecks of atheroma. Organizing thrombus in right pulmonary artery and its middle and lower lobe branches. Pulmonary arteriography showed left pulmonary artery and segmental branches to be enormously dilated. Lobular arteries ended abruptly and the finest branches were lost throughout most of lung, but peripheral pattern normal in some parts. Subpleural inter-pulmonary arterial anastomoses visible in several places.

Microscopy. Elastic arteries showed atherosclerosis and organizing thrombosis. Muscular arteries showed widespread occlusive disease, especially vessels with a diameter below $0.5 \mathrm{~mm}$. Process sometimes thrombotic, but elesewhere intimal proliferation was non-specific. Focal or diffuse attenuation of media was frequent in such stenosed or occluded arteries, some of them appearing as mere ghosts. Similar changes were present in arterioles. Abundant collateral channels. Bronchial arteries more numerous than usual. Venules showed moderate subendothelial thickening. One pulmonary infarct present.

Case 2. I. Y., aged 33, was a married woman without children. She had suffered from dyspnœa and cyanosis on effort since birth and attacks of palpitation latterly. During an attack of chorea at the age of 7 , a pulmonary systolic murmur was discovered. At the age of 24 she developed cardiac pain on effort, and shortly afterwards started having small hæmoptyses. At the age of 30, attacks of nocturnal dyspnœa commenced and she was unable to lie flat when she was admitted to hospital.

Examination. No definite cyanosis and no clubbing. Pulse normal; rhythm regular. BP 105/65. Jugular pulse normal. No odema. Right ventricular systolic lift. Early systolic sound audible in all areas. Systolic murmurs at tricuspid and pulmonary areas. Close splitting of the second sound with loud pulmonary element, followed by Graham Steell murmur. Hb, 125. RBC, 6.15. fields.

Radiology. Considerable enlargement of RA, and gross dilation of PA and its branches. Clear peripheral lung

EC. Extrasystoles and auricular tachycardia on occasions. S wave very deep in leads I and CR7, and absent in CR1 where $R$ was very tall. T wave inverted in III and in CR1, but upright in CR4. $P$ diphasic in CR1.

Cardiac Catheterization. PAP $100 / 50 \mathrm{~mm}$. Hg. Systemic flow 2.5 litres $/ \mathrm{min}$.; pulmonary flow $3.3 \mathrm{litres} / \mathrm{min}$.

Course. She developed a cough, severe hæmoptysis, and pleuritic left chest pain, and died a fortnight later.

Necropsy. Customary changes of heart failure in viscera. No thrombosis in heart or in pelvic or femoral veins.

Heart. Wt $645 \mathrm{~g}$. Great hypertrophy of RV $(1.5 \mathrm{~cm}$. thick). LV $1.6 \mathrm{~cm}$. thick. RA moderately dilated and hypertrophied. Atrial septal defect large enough to admit forefinger, immediately below entrance of SVC. Abnormal venous drainage of right lung, upper and middle veins entering SVC. FOC. 
Lungs. Left pleural cavity half full of blood-stained effusion. Recent large infarction of LLL. Pulmonary trunk and main branches dilated. Left pulmonary artery occluded by mass of recent thrombus.

Microscopy. Elastic arteries, showing old and recent thrombus, greatly narrowed in places. Widespread narrowing or occlusion of small muscular arteries by elastoid intimal proliferation, and sometimes thrombosis with canalization. Focal hypoplasia of media was a frequent finding. Disintegration of many small muscular arteries gave to them a ghost-like appearance. Adjacent to many of the obstructed arteries were thin-walled collateral vessels often containing organized thrombus. Arterioles frequently either partially or wholly occluded by intimal proliferation. Bronchial arteries and venules normal.

Case 3. P. A., a single woman, aged 32 , was first seen at 27. She had ill-defined rheumatism as a child. A heart murmur was noted at the age of 5 and restriction of activity was advised. In spite of this she was able to skate and dance a little up to the age of 24 . At 27 , she became very breathless after climbing two flights of stairs, and also had attacks of palpitation with sudden onset from childhood and more severe during past five years. When 29 , she had an attack of palpitation lasting several days and leading to cardiac pain and to unconsciousness, for which she was admitted to hospital.

Examination. Cyanosis, but no finger clubbing. Strawberry nævus on left cheek. Pulse small and irregular from extrasystoles; once auricular tachycardia. BP 110/75. Prominent $a$ wave in jugular veins. Apex beat in AAL. Striking systolic lift over right ventricle. Systolic thrill over pulmonary artery, second sound closely split, and its pulmonary element accentuated. First sound increased at apex and short mid-diastolic murmur heard. No œedema. $\mathrm{Hb}, 90$.

Radiology. Great enlargement of RA, RV, and especially of PA which bulged. Right and left branches dilated and abnormally pulsatile. Clear peripheral lung fields. Aortic knuckle small.

EC. S wave very deep in leads I and CR7, and absent in CR1 where $\mathrm{R}$ was tall. S-T segment depressed in leads II, III, and CR4 and T wave inverted in CR1. P waves not abnormal.

Catheterization. PAP $60 / 25 \mathrm{~mm}$. Hg. Systemic flow 4 litres/min.; pulmonary flow 11.5 litres $/ \mathrm{min}$. Pulmonary vascular resistance approximately 3 units.

Course. Because her effort tolerance had decreased steadily during the past three years, surgical closure of the septal defect was advised and the patient was re-admitted to hospital. Catheterization then showed a right ventricular systolic pressure of $75 \mathrm{~mm}$. Hg, a systemic flow of 2.75 litres/min., and a pulmonary flow nearly twice as great. The pulmonary vascular resistance had risen to about 10 units. The patient died from intractable ventricular fibrillation the day after the defect had been closed.

Necropsy. Moderate congestion of viscera. No thrombosis in heart or in systemic veins.

Heart. Wt $505 \mathrm{~g}$. Sutured atrial septal defect $3 \mathrm{~cm}$. long. Mitral stenosis, admitting one finger with difficulty. Great hypertrophy and dilatation of RV $(0.9 \mathrm{~cm}$. thick) and RA. Hypertrophy of LA. LV small $(1.4 \mathrm{~cm}$. thick).

Lungs. PA greatly dilated $(9.0 \mathrm{~cm}$. circumference; aorta, $5.5 \mathrm{~cm}$.) showing numerous flecks of atheroma, but no thrombosis or infarction. Pulmonary arteriography showed left pulmonary artery and segmental branches to be greatly dilated, but lobular arteries smaller than normal and finest branches lost throughout. One small infarct.

Microscopy. Flecks of atheroma in elastic arteries. Great majority of muscular arteries less than $0.2 \mathrm{~mm}$. diam., narrowed or occluded by elastoid intimal proliferation. Focal or diffuse medial thinning frequently present in these vessels. Many muscular arteries contracted, some being as small as $0.04 \mathrm{~mm}$. in diameter. Many arterioles narrowed by intimal proliferation. Endothelial thickening conspicuous in venules. Bronchial arteries normal.

\section{Incidence}

Bedford et al. (1957) diagnosed obstructive pulmonary hypertension in 15 of their 100 cases of atrial septal defect, and Campbell et al. (1957) found a high pulmonary vascular resistance in 20 per cent of their 46 cases investigated by cardiac catheterization. These figures agree closely with those of Wood (1956) who found extreme pulmonary hypertension in 16 per cent of his cases with an atrial septal defect large enough to permit a pulmonary flow three times as great as the systemic flow.

In Wood's series, an average age of 22 years in those with a high pulmonary vascular resistance was similar to that in cases of uncomplicated atrial septal defect, namely 23 years, but in both Bedford's and Campbell's series, the patients with pulmonary hypertension tended to be older. Thus, in Bedford's series, 62 per cent were under 30, but only 6 of the 15 with pulmonary hypertension; 3 of the 15 were between 30 and 40 years, and 6 were over 40 . Similarly, in Campbell's series 67 per cent were under 30, but only 2 of his 9 cases of pulmonary hypertension were in this group; the ages of the remaining 7 were between 33 and 52. Our three cases were aged 32, 33, and 52 years at death. It would seem, therefore, that pulmonary hypertension in atrial septal defect rarely proves fatal before the age of 25 years.

There are no reliable data concerning the sex incidence of pulmonary hypertension in association with atrial septal defect. In uncomplicated cases the female to male ratio is approximately 2.5 to 1 (Bedford et al., 1957; Campbell et al., 1957). Our three patients were women. 


\section{Clinical Features}

These simulated those found in solitary pulmonary hypertension (Evans et al., 1957), and included dyspnœa, cardiac pain, syncope, cyanosis, a small pulse, low blood pressure, a prominent atrial pulse in the neck, increased right ventricular pulsation, close splitting of the second heart sound with accentuation of its pulmonary component, and a Graham Steell murmur of pulmonary incompetence. A variation in some of these signs caused by the septal defect, however, requires special mention.

Palpitation was a prominent symptom in each of our three patients; extrasystoles and auricular tachycardia were present in all, and in one auricular fibrillation and auricular standstill had also taken place. When arrhythmia is a prominent feature in pulmonary hypertension, and when mitral stenosis is absent, it suggests the presence of atrial septal defect. Cyanosis was conspicuous in two of the three and appeared on effort in the third. Finger clubbing was absent even in the patient in whom cyanosis was alleged to have been present from birth.

Outward displacement of the apex beat as far as the anterior axillary line was a noticeable feature in all three cases. Such a degree of cardiac enlargement is unusual in pulmonary hypertension, so that its presence suggests an associated atrial septal defect. Conspicuous enlargement of the pulmonary artery also suggested the diagnosis of atrial septal defect in our cases known to have pulmonary hypertension. Such a change gave prominence to other physical signs, namely, visible and palpable pulsation over the pulmonary artery, a systolic thrill, a diastolic shock, a loud and often rough systolic murmur, and an obvious Graham Steell murmur.

The Electrocardiogram. The QRS complex in the right pectoral lead is abnormal in the majority of patients with atrial septal defect (Barber et al., 1950; Bedford et al., 1957). Although the deformity has usually been referred to as incomplete or complete right bundle-branch block, Taimont et al. (1952) believed that when the QRS did not exceed $0 \cdot 1 \mathrm{sec}$. it was evidence of right heart hypertrophy, while Walker et al. (1956) believed that the secondary $\mathrm{R}$ wave of the curve was the result of selective hypertrophy of the basal portion of the right ventricle. Campbell et al. (1957) have advised that the terms incomplete bundle-branch block should be abandoned when describing the cardiogram of atrial septal defect, and proposed that direct reference should be made to the presence of primary and secondary $R$ waves, and to the width of the QRS complex.

Wagner and Graham (1957) found that there was always cardiographic evidence of right ventricular hypertrophy when the pulmonary artery pressure was high, and that it was often present in patients whose pressure was normal. It appeared to them that "increased flow hypertrophy" was indistinguishable from "pressure hypertrophy."

It is clearly important to determine whether true pulmonary hypertension, as defined in this paper, due to obstruction within the lesser pulmonary arteries, can be recognized from the cardiogram. We, therefore, examined the tracing in 50 adult patients with this congenital anomaly, and found three distinctive patterns in each of the two groups.

Thus, in uncomplicated atrial septal defect (Fig. 1), the first pattern consisted of a deep $S$ wave in leads I and CR7, an $R$ wave greater or slightly less than $S$ in CR1 where the $T$ wave was inverted, and no widening of the QRS period. In the second pattern the QRS period was widened to $0 \cdot 1 \mathrm{sec}$., and an $\mathrm{RSR}^{\prime}$ type of curve appeared in CR1. The third pattern was similar to the former except that a RSR' $\mathrm{S}^{\prime}$ complex appeared in CR1. A slight variant of this curve appeared in three instances (Fig. 3). It so happened that complete right bundle-branch block with a QRS measuring at least $0.12 \mathrm{sec}$. was not met with in this group, nor was a qRS pattern in either group.

When the atrial septal defect was associated with pulmonary hypertension there were also three distinctive cardiograms (Fig. 2). In the first pattern there was lengthening of the QRS period to $0.1 \mathrm{sec}$; in $\mathrm{CR} 1$ the $R$ was tall and the $S$ wave correspondingly short, while the $T$ wave was inverted or depressed in this lead and in leads to the left as far as CR4; the T was also inverted in leads III and IIIR and somewhat depressed in lead II. It is these features that indicate conclusively the presence of pulmonary hypertension in atrial septal defect. Bedford (1957) has found the same criteria to apply in his patients. In the second pattern, in addition to the changes just described, a 


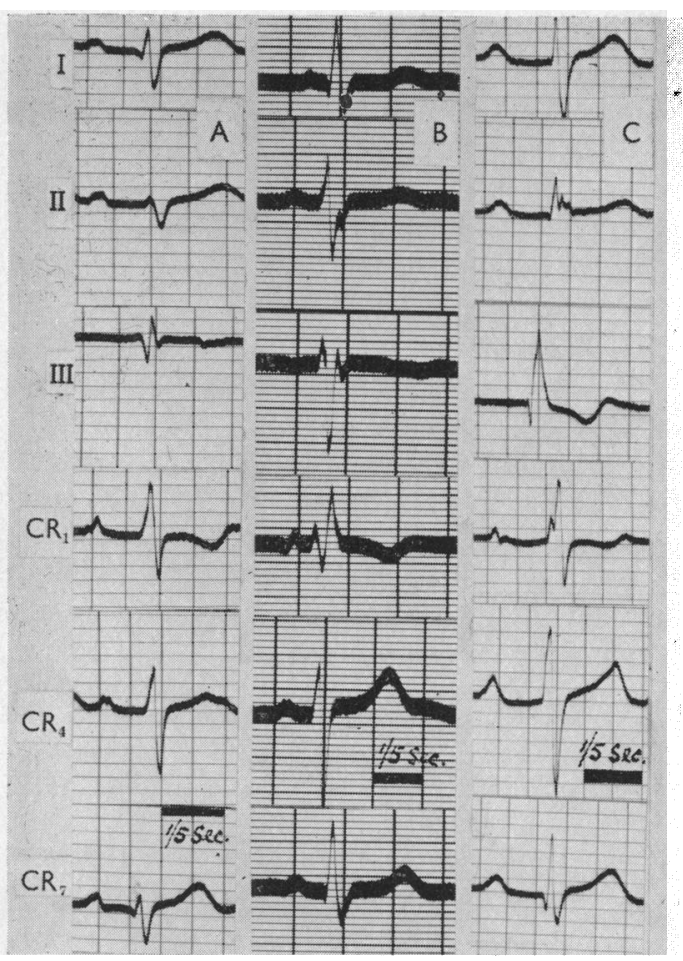

FIG. 1.-Uncomplicated Atrial Septal Defect. Three common electrocardiographic patterns. (A) Deep $S$ wave in leads $I$ and $C R 7$, an $R$ wave greater than $S$ in CR1 where $T$ is inverted, and no widening of QRS complex. (B) Widening of QRS to 0.1 sec., with an $\mathrm{RSR}^{\prime}$ pattern in CR1. (C) Similar to (B) except for an RSR'S' complex in CR1.

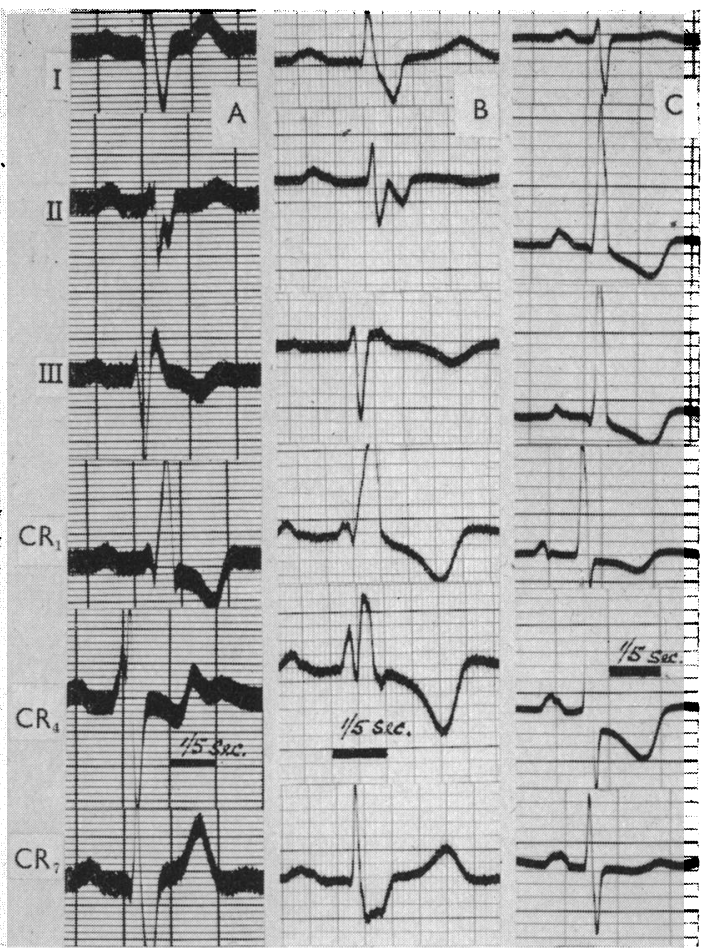

Fig. 2.-Atrial Septal Defect and Pulmonary Hypertension. Three common electrocardiographic patterns. (A) Lengthening of QRS period, tall $\mathrm{R}$ in CR1 with inversion or depression of $T$ wave in this lead and in leads as far to the left as CR4; $\mathrm{T}$ is also inverted in leads III and IIIR (not shown), and depressed in II. (B) Similar to (A) with the addition of greater widening of QRS to $0 \cdot 15 \mathrm{sec}$., constituting bundle-branch block. (C) Similar to (A) except that there is no widening of QRS which shows an RS pattern in CR1.
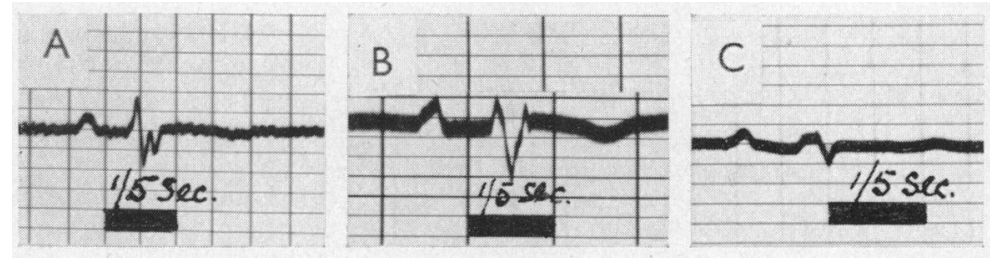

FIG. 3.-Uncomplicated Atrial Septal Defect. Three less common patterns of QRS complex in CR1.

characteristic curve of complete right bundle-branch block with its wide QRS period of 0.12 sec. or over, was present. In the third pattern the changes were identical with those in the first except that the QRS period was of normal length with an RS design in CR1.

Auricular arrhythmia was present in five patients with pulmonary hypertension and in one without. This finding, therefore, especially in a young patient with atrial septal defect, suggests 
the presence of pulmonary hypertension, and in one with hypertension it points to the association of atrial septal defect unless mitral stenosis is present.

Radiology. There is great enlargement of the pulmonary artery and its primary branches which on screening are seen to pulsate excessively unless occluded by thrombus, as sometimes happens. The periphery of the lung fields is clear. There is considerable enlargement of the right atrium and ventricle. The aortic knuckle is either small or hidden by the distended pulmonary artery (Fig. 7).

Cardiac catheterization in two of our patients established the diagnosis of atrial septal defect with pulmonary hypertension, but this test was considered to be an unjustifiable risk in the third, as indeed it is in many patients with severe pulmonary hypertension.

Treatment. In our view the surgical closure of atrial septal defect when complicated by pulmonary hypertension, as defined in this paper, is never justified. Not only is the procedure hazardous, but in view of the obstructive lesions that abound in the lesser pulmonary arteries, it can never do good. This opinion is shared by Bedford et al. (1957) who state that pulmonary hypertension of the hyperkinetic type, due to a large flow and not to a seriously raised vascular resistance, is no contra-indication to surgical treatment, but that obstructive pulmonary hypertension is another matter. Moreover, they opine that even when the shunt is from left to right, closure of an atrial septal defect in the presence of severe pulmonary vascular disease removes the safety-valve action of a potential right-to-left shunt during exertion and so virtually enhances the hypertension.

\section{Pulmonary Hypertension in Ventricular Septal Defect Case Reports}

Case 4. J. L., a single woman, aged 30, was first seen when 28 . She had always been somewhat short of breath.

Examination. No cyanosis or clubbing. Pulse normal. BP 120/70. Apex beat just outside MCL. Palpable impulse and systolic thrill over a wide area to the left of the sternum. Rough and long systolic murmur heard in all areas and especially loud in the fourth left intercostal space. Second sound rather loud and apparently single, immediately followed by a moderately rough early diastolic murmur. A murmur in mid-diastole was audible in the mitral area. Hb, 85. RBC, 5.

Radiology. Moderate enlargement of RA and RV. Considerable enlargement of PA and of its branches which showed increased pulsation. Clear peripheral lung fields.

EC. Sinus rhythm. S wave very deep in leads I and CR7 and absent in CR1. T wave upright in leads II and III, inverted in CR1 and depressed in CR4. S-T depressed in I and R very tall in CR7. P wave inverted in leads II, III, CR4, and CR7, and very tall and spiky in CR1.

Course. Two years later, attacks of unconsciousness were followed by retrosternal pain. Signs unchanged. Four weeks later, the patient died suddenly in a train.

Necropsy. Customary changes of heart failure in viscera. No thrombosis in heart or in systemic veins.

Heart. Wt $575 \mathrm{~g}$. Great hypertrophy of RV $(1 \cdot 1 \mathrm{~cm}$. thick). Moderate hypertrophy of $\mathrm{LV}(1.8 \mathrm{~cm}$. thick). Defect $(1.8 \mathrm{~cm}$. diameter) in the membranous portion of the interventricular septum. PFO (valvular). Fenestration of aortic cusps.

Lungs. PA showed scanty atheroma. Several small branches filled with recent thrombus.

Microscopy. Elastic arteries normal. Muscular arteries showed a remarkable degree of contracture, the larger ones presenting thick media and prominent internal elastic lamina. Many smaller muscular arteries were of arteriolar size, some having a diameter of only $0.04 \mathrm{~mm}$. Intimal proliferation present in a few muscular arteries with segmental hypoplasia of media. Many arterioles showed pallisading of endothelial nuclei around narrowed lumen. Bronchial arteries normal.

Case 5. A. M., aged 20, was admitted to hospital with a staphylococcal pyæmia. Although he had been blue from birth, he had suffered no great disability and was able to work as a clerk until his recent illness.

Examination. Obvious cyanosis and some clubbing of fingers. Pulse small. BP 110/80. No œdema. Apex beat in AAL. Systolic murmur and loud Graham Steell murmur at left sternal border. Hb, 100.

Radiology. Moderate enlargement of RA and RV. Great enlargement of PA and its branches traceable almost to the periphery of the lungs. Some hilar clouding.

Course. The patient died from pyæmia after an illness lasting 5 days. An electrocardiogram was not recorded.

Necropsy. Customary changes of heart failure and of septicæmia in viscera. Numerous miliary pyæmic abscesses in liver. No thrombosis in heart or in systemic veins.

Heart. Wt $640 \mathrm{~g}$. Great hypertrophy of RV $(0.7 \mathrm{~cm}$. thick), and considerable hypertrophy of LV $(2 \cdot 0 \mathrm{~cm}$. thick). Defect $(3.5 \mathrm{~cm}$. diam.) in membranous part of interventricular septum. The aorta which was hypoplastic, arose mainly from the RV. The PA arose equally from both ventricles. FOC.

Lungs. Great dilatation of pulmonary trunk $(11 \mathrm{~cm}$. circumference; aorta $5.5 \mathrm{~cm}$.) and its branches. Scanty atheroma in these vessels, but numerous patches in the intrapulmonary arteries.

Microscopy. Elastic arteries showed moderate atherosclerosis. Muscular arteries, especially vessels with a diameter below $0.6 \mathrm{~mm}$. diameter, partly or wholly occluded by intimal próliferation which lay adjacent to areas of 
hypoplasia and aplasia of media. Thrombosis with re-canalization of some muscular arteries. Arterioles showed similar, though less severe changes. Bronchial arteries and venules normal.

Case 6. L. P., a man, aged 36, had been blue for as long as he could recall. A heart lesion had been discovered at the age of two years. He had never been able to run, and was breathless on hills. When 31, he was admitted to hospital for investigation. His symptoms had not increased since the age of 15 , and during this time he had suffered from recurrent cough, bronchitis, and hæmoptysis.

Examination. There was moderate cyanosis and clubbing of fingers. The pulse was natural. BP, 150/90. Jugular venous pulse and pressure normal. Systolic lift over RV. Palpable diastolic shock and thrill to left of sternum. Pansystolic murmur, audible all over præcordium, maximal in fourth left intercostal space. Second sound in pulmonary area loud and single, though splitting was just detected on deep inspiration. Graham Steell murmur heard once. $\mathrm{Hb}, 150 ; \mathrm{RBC}, 6 \cdot 6$. Cardiac catheterization showed a high PAP 130/64 mm. Oxygen saturation, femoral artery, 89 per cent.

Radiology. Moderate enlargement of heart to right and left. Similar enlargement of PA and its primary branches which pulsated obviously. Lung fields normal. Angiocardiography showed early filling of a normal sized aorta.

EC. Deep $S$ wave in leads I and CR7. T low in II, inverted in III and in CR1 where $R$ was tall and $S$ absent.

Course. Hæmoptysis recurred, but without general deterioration until the age of 35 when cyanosis and breathlessness increased and intermittent claudication set in. He was admitted with symptoms of pulmonary infarction. Five days later, he collapsed while sitting on a bedpan and died suddenly.

Necropsy. Congestion of viscera. No thrombosis of heart or systemic veins.

Heart. Wt $700 \mathrm{~g}$. Great hypertrophy of RV. Small atrial septal defect. Aorta, over-riding the ventricular septal defect, was $2.5 \mathrm{~cm}$. diameter at its commencement, gradually tapering to $1.0 \mathrm{~cm}$. diameter, but without coarctation.

Lungs. PA greatly dilated with flecks of atheroma. Recent infarct in LLL.

Microscopy. Elastic arteries showed occasional plaques of atherosclerosis and recent thrombosis. Large muscular arteries frequently abnormal, showing aplasia of the media, with overlying intimal proliferation or organizing thrombosis, and involving either a segment of an artery or its entire circumference. Adjacent to many of these arteries were thin-walled collateral vessels, some of them containing organized thrombus. Majority of small muscular arteries greatly narrowed by thrombus. In these arteries the internal elastic lamina was exceptionally thick and overlaid with intimal proliferation which mainly consisted of layers of elastic fibres. Disintegration of many small muscular arteries gave to them a ghost-like appearance. Arterioles partially or wholly occluded by intimal proliferation. Bronchial arteries and venules normal.

\section{Incidence}

The incidence of pulmonary hypertension in ventricular septal defect is difficult to determine, partly because the isolated fistula is not so common as was thought, and partly because of the confusion arising from the use of the term, Eisenmenger complex. In this paper a case where the aorta over-rode the right ventricle is not kept apart from cases of septal defect with pulmonary hypertension in whom the aortic root was normal. Wood et al. (1954) found severe hypertension in 24 per cent of their cases of isolated septal defect, but the incidence rises to 57 per cent if cases with a defect less than $1 \mathrm{~cm}$. in diameter are excluded (Wood, 1956).

Wood found the average age of uncomplicated ventricular septal defect to be 13 years compared with 22 years for those with pulmonary hypertension. On the other hand, among 20 patients with hypertension reported by DuShane et al. (1956), 19 were children under 12 years of age. Three of the six patients reported by Brown et al. (1955) were also aged 16 year or under. Selzer and Laqueur (1951) reviewed 35 cases of Eisenmenger complex examined at necropsy and found that the majority died in the third or fourth decade, although three had survived beyond the age of 50 . Our three patients died at the age of 20,30 , and 36 years respectively.

The sex incidence appears to be the same whether pulmonary hypertension is present or absent. In the isolated fistula, male and female patients are equally affected. In the series with hypertension reported by Selzer and Laqueur (1951) 55 per cent were male. Two of our patients were men and one a woman.

\section{Clinical Features}

Cyanosis is often slight. Thus, it was absent in four cases described by Espino-Vela and Mata (1956) and inconspicuous in the six patients reported by Brown et al. (1955). It was absent in one of our patients, but obvious in the other two and associated with clubbing of fingers.

The pulse is not necessarily small in pulmonary hypertension associated with ventricular septal 
defect. The pansystolic murmur, characteristic of lone ventricular septal defect tends to shorten into a mid-systolic murmur with the advent of pulmonary hypertension (Fig. 4), and in four of the six cases reported by Brown et al. (1955) the systolic murmur was absent. A pansystolic murmur accompanied by a thrill was, however, present in two of our cases, but in the third the murmur was shorter and softer. A Graham Steell murmur was present in two cases.

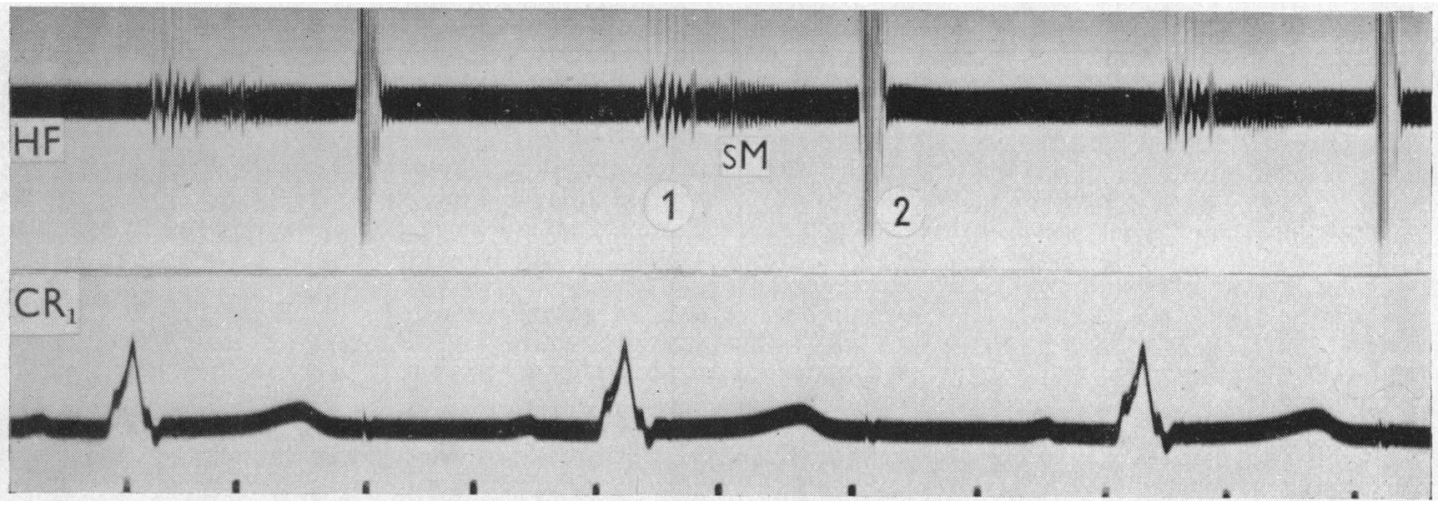

Fig. 4.-Ventricular Septal Defect and Pulmonary Hypertension. Attenuated murmur limited to mid-systole.

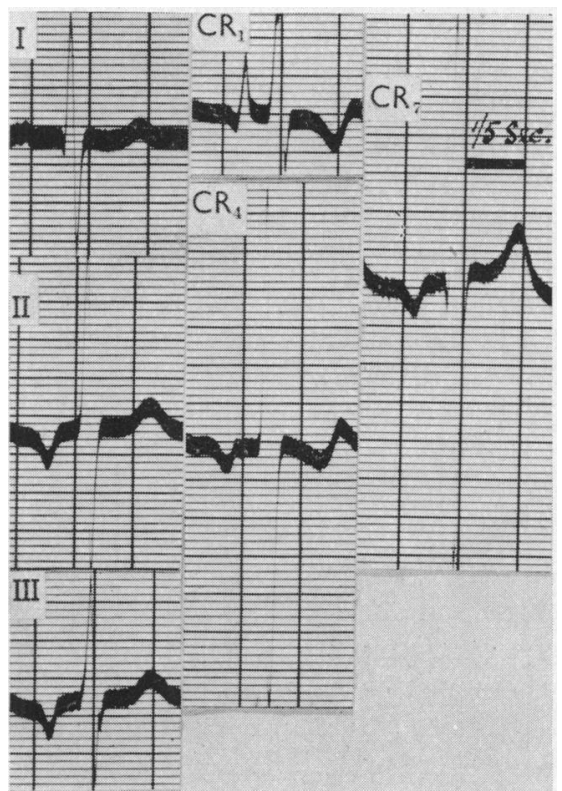

Fig. 5.-Ventricular Septal Defect and Pulmonary Hypertension. Tall $\mathrm{R}$ and very tall $P$ with inversion of $T$ in CR1, and $\mathrm{S}-\mathrm{T}$ depression in CR4, indicate hypertrophy of RA and RV. S-T distortion in $I$ and $Q$ and very tall $R$ waves in CR7 suggest associated left ventricular hypertrophy. Case 4.

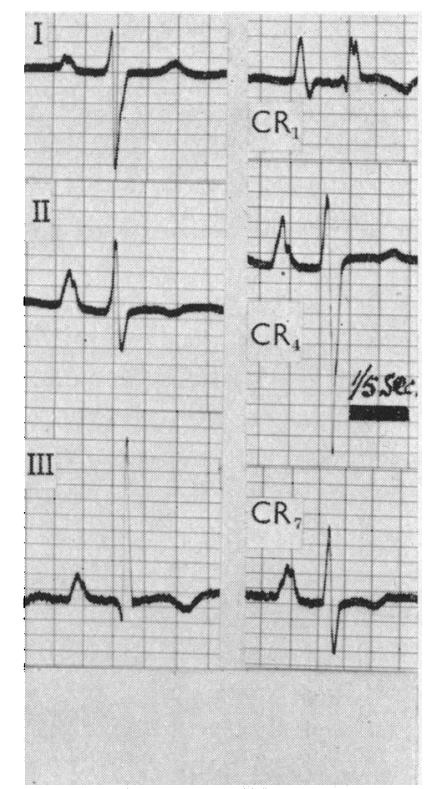

Fig. 6.-Patent Ductus Arteriosus and Pulmonary Hypertension. S-T depression in CR7 suggests left ventricular hypertrophy. Other changes typify right atrial and right ventricular hypertrophy. Case 9. 
The Electrocardiogram. In uncomplicated ventricular septal defect the tracing is normal when the shunt is small, and often when it is of moderate size. When the shunt is large, evidence of enlargement of both ventricles may appear. Thus, a secondary $\mathrm{R}$ wave may appear in right-sided leads, and a $\mathrm{Q}$ wave followed by a tall $\mathrm{R}$ wave in left-sided leads (Wood et al., 1954). In the presence of pulmonary hypertension the cardiogram shows mainly right heart preponderance, but as happened in one of our three cases there is sometimes evidence of left ventricular hypertrophy (Fig. 5).

Radiology. According to Brown et al. (1955) radiological examination of the heart shows that the pulmonary artery is not as large when pulmonary hypertension complicates ventricular septal defect as in the case of atrial septal defect. Campbell (1951), on the other hand, found very large pulmonary arteries in this anomaly. Our three patients showed moderate enlargement of the heart and similar or greater enlargement of the pulmonary arterial trunk and its main branches (Fig. 8 and 9).

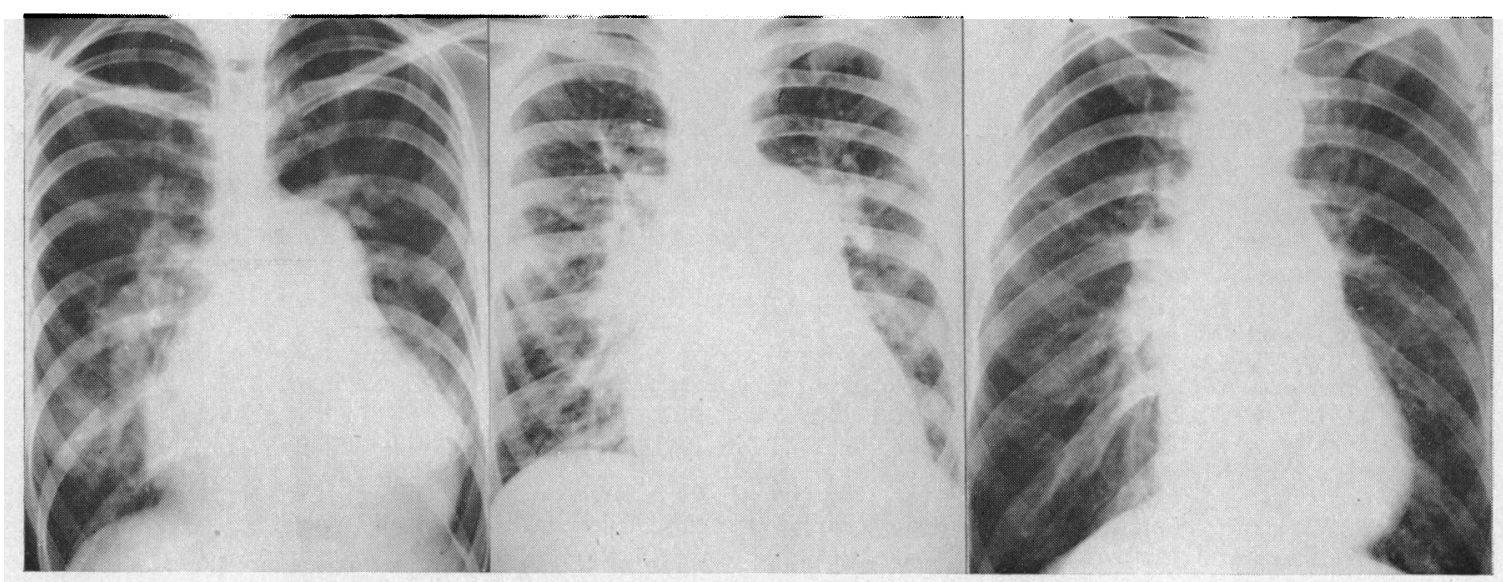

FIG. 7.-Atrial Septal Defect and Pulmonary Hypertension. Great enlargement of PA and its branches. Periphery of lung fields clear. Considerable enlargement of RA and RV. Case 3.
FIG. 8.-Ventricular Septal Defect and Pulmonary Hypertension. Moderate enlargement of RA and LV. Great enlargement of PA and its branches which are seen as far as the periphery. Case 5 .
FIG. 9.-Ventricular Septal Defect and Pulmonary Hypertension. Apparent prominence of LV. Enlargement of RV in left oblique. Moderate enlargement of PA and its primary branches. Lung fields normal. Case 6.

Cardiac catheterization was performed in one of our cases, but the investigation afforded no evidence of the site of the shunt, and the test has a limited value, in addition to carrying some risk, in these patients. Similarly, angiocardiography is not invariably helpful (Campbell and Hudson, 1951).

\section{Pulmonary Hypertension in Patent Ductus Arteriosus Case Reports}

Case 7. I. W., a single woman aged 22, was born with Madelung's deformity with absence of both radii and thumbs. She was otherwise well until the age of 14 when she became breathless on effort and developed a productive cough. At the age of 18 the dyspnœa and cough were worse and a year later she attended hospital.

Examination. Slight cyanosis, but no clubbing. Pulse small. BP 110/80. Split second sound with loud pulmonary element. Graham Steell murmur. Triple rhythm due to addition of the third heart sound.

Radiology. Slight enlargement of RA, considerable enlargement of RV and of pulmonary trunk. Right and left PA and their branches dilated and pulsatile. Peripheral lung fields normal.

$E C$. $\mathrm{S}$ wave very deep in lead I, and small in CR 1 where $\mathrm{R}$ was very tall. $\mathrm{S}-\mathrm{T}$ depressed in II and $\mathrm{T}$ wave inverted in leads III and CR1. P wave tall in II and tall and spiky in CR1. 
Course. At the age of 21, œdema appeared and persisted in spite of mercurial injections, and she was later admitted to hospital with dyspnœa, cough, œdema, and hoarseness. Cyanosis was then evident and the pulse was small. BP 105/80. The liver edge was just felt and there was gross œema of the legs and thighs. Hb, 125. RBC, 11·2. Her condition continued to deteriorate, with severe attacks of dyspnœa and increasing cyancsis. She developed pulmonary infarction and died a fortnight later.

Necropsy. Customary changes of heart failure in viscera. No thrombosis in systemic veins. Other congenital malformations apart from the heart and Madelung's deformity included absence of left uterine cornu and left Fallopian tube; left kidney lay just above right pelvic brim and was somewhat mis-shapen.

Heart. Very great hypertrophy, without dilatation of RV $(1.4 \mathrm{~cm}$. thick). LV normal. RA greatly dilated. RA and RV contained loosely-attached thrombus. Slight fibrous thickening of pulmonary valve cusps. FOC. Ductus arteriosus $(0.9 \mathrm{~cm}$. diameter). Descending aorta and left PA contiguous at site of fistula.

Lungs. Hæmorrhagic infarction of entire RUL. PA trunk greatly dilated. (PA $7.5 \mathrm{~cm}$. circumference; aorta $5.5 \mathrm{~cm}$.). Severe atheroma in both large and small branches of PA. Artery to RUL occluded by embolus.

Microscopy. Extensive atherosclerosis in elastic arteries. Muscular arteries showed very widespread occlusive changes, with hardly a normal muscular artery to be seen. Breaks in walls of muscular arteries in places with external herniation of reactive fibrous tissue. Hypoplasia and sometimes aplasia of media adjacent to occlusive intimal proliferation. Abundant collateral channels, especially in vicinity of occluded arteries. Majority of arterioles occluded by intimal proliferation similar to that in muscular arteries. Bronchial arteries prolific. Venules normal.

Case 8. A. B., married woman, aged 24 , said to have had heart disease from birth. While at school she could not play games because of shortness of breath, throbbing in the neck, and aching in the gums. She became cyanosed when cold, and suffered from a cough every winter. When 17 she was advised that her heart disease was not suitable for operation and was warned against having children. Attended hospital when three months' pregnant at the age of 23.

Examination. Slight central cyanosis. No clubbing of fingers. Pulse small. BP, 90/70. Jugular pulse showed prominent $a$ wave. Pulsation in supra-sternal notch, and over the conus of RV and PA. Apex beat a little out. Palpable pulmonary valve closure. Second sound split in pulmonary area with loud pulmonary component. Short systolic murmur and thrill in PA.

Radiology. No generalized enlargement of the heart. Moderate enlargement of RA, and similarly of PA with slight pulmonary plethora. Aorta normal.

$E C$. S wave very deep in leads I and CR7 and equal to tall $\mathrm{R}$ in CR1 where $\mathrm{S}-\mathrm{T}$ segment was depressed. T low only in lead III. P waves normal.

Course. Breathlessness increased during pregnancy, and was accompanied by hæmoptysis and œdema of the ankles. On admission to hospital the jugular venous pressure was raised to $5 \mathrm{~cm}$. Considerable œdema of feet and legs. Hb, 113. WBC, 9.2. WR negative. Shock and unconsciousness developed during third stage of premature labour at 36 weeks. Became febrile, with rising pulse rate and deep central cyanosis, and died in coma on the fifth day of the puerperium.

Necropsy. Moderate congestion of viscera. No thrombosis in heart or in systemic veins.

Heart. Wt $305 \mathrm{~g}$. Patent ductus arteriosus ( $1 \mathrm{~cm}$. diameter); left PA and aorta contiguous at site of fistula. RV moderately dilated and greatly hypertrophied $(1 \mathrm{~cm}$. thick). LV normal $(1 \cdot 2 \mathrm{~cm}$. thick). Fused and depressed commissure between small left and right coronary cusps of aortic valve of congenital origin.

Lungs. No infarction or thrombosis. Very severe atheroma extending down to segmental branches and confluent in main trunk.

Microscopy. Elastic arteries normal. Widespread occlusive changes in muscular arteries, and mainly in vessels with diameter below $0.5 \mathrm{~mm}$. Such intimal proliferation frequently appeared as elastoid reaction. Focal or diffuse attenuation of media common in occluded or stenosed arteries. Some otherwise normal muscular arteries in state of contracture, with diameter as small as $0.06 \mathrm{~mm}$. Majority of arterioles occluded by tissue similar to that in muscular arteries. Abundant collateral channels, many filled with intimal proliferation. Bronchial arteries and venules normal.

Case 9. E. G., married woman without children, aged 35, had been blue since the age of 14 . She became breathless on effort at 29 , when a diagnosis of congenital heart disease was made. She remained fairly well until she was 38 , when she started having recurring hæmoptysis. Ten years later, dyspnœa became worse and œdema of the ankles developed. She was admitted to hospital following a large hæmoptysis.

Examination. Intense cyanosis, but no clubbing. Pulse regular and of good volume. BP, 140/80. Jugular venous pressure raised $3 \mathrm{~cm}$. Apex beat just outside MCL. Right ventricular systolic lift. Palpable pulmonary valve closure. Sound in early systole in pulmonary area. Closely split second sound with loud pulmonary element. No murmurs heard. Hb, 130 . RBC, 10.4.

Radiology. Only slight enlargement of heart, and RA not prominent. PA enlarged and bulging slightly from pulmonary bay; its primary branches conspicuous with calcium in their walls. Peripheral lung fields relatively clear. Aorta dilated and calcified.

$E C$. Sinus rhythm. S wave very deep in leads I and CR7 and absent in CR1 where R was tall. T wave low in I, and CR4 and inverted in II, III, CR1, and CR7. Tall P in II, CR1, CR4, and CR7.

Course. Re-admitted to hospital at age of 52 with heart failure. Graham Steell murmur audible. Several further hospital admissions for pulmonary infarction with fatal pulmonary embolism ultimately.

Necropsy. Congestion of viscera. No thrombosis in heart or in systemic veins.

Heart. FOP (valvular). Great hypertrophy without dilatation of RV $(1.2 \mathrm{~cm}$. thick). LV normal $(1 \cdot 5 \mathrm{~cm}$. thick). Both atria normal. Calcification of pulmonary and tricuspid valve cusps. Aorta communicating directly with left PA by orifice of 1.5 by $0.8 \mathrm{~cm}$. Calcified and ulcerated atheromatous plaque in aorta opposite ductus.

Lungs. Gross dilatation and calcification of pulmonary trunk and both branches. Confluent atheroma and calcification extending to branches of segmental arteries. Thrombus in right pulmonary artery. Several infarcts of vary- 
ing ages in right lung. Bronchial arteries normal. Pulmonary arteriography showed left PA and segmental branches to be of normal calibre. Widespread occlusion of lobular arteries and loss of finest branches. Inter-pulmonary arterial anastomoses.

Microscopy. Severe atherosclerosis in elastic arteries whose media showed abundance of elastic laminæ suggesting arterial contracture. Scarcely a single muscular artery normal, the great majority being occluded, and many in course of disintegration. Occlusive process sometimes thrombotic. Great elastoid intimal proliferation. Media showed focal or diffuse hypoplasia and often aplasia. Collateral channels abundant both in vicinity of obliterated muscular arteries and beneath pleura. Most arterioles narrowed or occluded by intimal proliferation. Venules showed great endothelial thickening. Bronchial arteries prolific.

Case 10. J. M., a girl aged 15. A heart murmur had been discovered at the age of 4 , cyanosis at 5 , and scoliosis at 7 years. At 14, dyspnoea became evident and cyanosis had increased. She also developed aching in the jaw on effort.

Examination. Central cyanosis, but no clubbing. Pulse small. BP 110/95. Giant $a$ wave in neck. Apex beat just outside MCL. Right ventricular pulsation in epigastrium. Pulmonary valve closure palpable. Sound in early systole and moderate systolic murmur in pulmonary area. Second sound closely split with loud pulmonary element. Severe kyphoscoliosis.

Radiology. Moderate enlargement of RA and RV. PA filling pulmonary bay. Right PA and segmental branches normal. Peripheral lung fields clear. Aorta small. Marked kyphoscoliosis.

$E C$. $\mathrm{S}$ wave very deep in leads $\mathrm{I}$ and $\mathrm{CR} 7$ and small in CR1 where $\mathrm{R}$ was tall. $\mathrm{T}$ wave inverted in leads II, III, and CR1. S-T depressed in CR7. $P$ wave tall in lead II and tall and spiky in CR1.

Course. When admitted to hospital a pulmonary diastolic murmur was present. No œdema. Hb, 118. WBC, 9.6. Cardiac catheterization was attempted, but the patient's condition prevented completion of the test. She died suddenly a month after discharge from hospital and nine months after noticeable increase in breathlessness.

Necropsy. (Permission to examine heart and lungs only.)

Heart. Wt $280 \mathrm{~g}$. Great hypertrophy of RV, which was as thick as $\mathrm{LV}(1.0 \mathrm{~cm}$.). Patent ductus arteriosus, $1 \mathrm{~cm}$. long and $1 \mathrm{~cm}$. wide. No thrombosis.

Lungs. Occasional small plaques of atheroma in dilated PA trunk and main branches.

Microscopy. (Only two blocks were available for histological examination.) Elastic arteries normal. Large and medium-sized muscular arteries also normal apart from occasional thrombosis. Most conspicuous abnormality was contracture of small muscular arteries, some of which were no more than $0.04 \mathrm{~mm}$. in diameter; a few showed slight intimal proliferation adjacent to areas of medial hypoplasia. Arterioles, venules, and bronchial arteries normal. Moderate emphysema.

\section{Incidence}

The diagnosis of pulmonary hypertension and patent ductus arteriosus was an infrequent event ten years ago, and even now it is not commonplace. Nevertheless, the dual lesion is not rare. Among 272 cases of patent ductus, Ellis et al. (1956) found $45(16 \%)$ with a systolic pulmonary pressure of $60 \mathrm{~mm}$. Hg or higher. Pedersen et al. (1956) found a systolic pressure of $80 \mathrm{~mm}$. in 18 of 107 cases, and Lequime et al. (1956) reported considerable pulmonary hypertension in 15 per cent of their series. Campbell (1955) when collecting 160 cases of patent ductus arteriosus without pulmonary hypertension in the sense used here met with six with hypertension, and we encountered eight instances showing right ventricular preponderance in the electrocardiogram when assembling 100 uncomplicated cases.

Until recently most of the reported cases of patent ductus arteriosus with pulmonary hypertension have been adults. Thus, Anderson et al. (1956), reporting on 10 cases in children, reviewed 45 published cases with reversed or bi-directional flow, and only 5 of these were under 10 , while 19 were over 30 years of age. Among 30 cases reported by Sones (1956), 18 were infants under 2 years, though his diagnosis of hypertension rested on manometric readings. Wood (1956) found an average of 16 years in his cases with hypertension to be almost identical with that in cases of uncomplicated patent ductus. The ages of our 4 cases at death were $15,22,24$, and 55 years.

In Abbott's (1936) series of simple patency of ductus arteriosus the female incidence was about twice as common as the male, and Cosh (1957) found a female preponderance of 2.7 to 1 in his series. A slightly greater female preponderance is found when pulmonary hypertension is associated with the patent ductus. Thus, of the 45 cases reviewed by Anderson et al. (1956), 32 were female and 13 male. Four out of eight cases reported by Hultgren et al. (1953) were female, seven out of eight reported by Whitaker et al. (1955), and five out of six reported by Campbell (1955). Our four cases were female. 


\section{Clinical Features}

Although cyanosis was present in each of our four cases, it was prominent in only one (Case 9) where there was thrombosis of the main branches of the pulmonary artery with noticeable calcification of their walls as far as the segmental branches. Clubbing of the fingers was never seen. Greater cyanosis in the lower than in the upper limbs has sometimes been described in patients in whom the shunt through the ductus has become reversed, but this differential cyanosis was not seen in our cases.

When pulmonary hypertension complicates patent ductus arteriosus the pulse is usually small, and a pulmonary diastolic shock is generally present. The typical continuous or Gibson murmur is absent. In three of our four cases a Graham Steell murmur was audible, and in two a systolic murmur. The absence of a Gibson murmur is significant. In early infancy when the systemic pressure is low and the pulmonary arterial pressure relatively high (Hamilton et al., 1937; Barclay et al., 1944), the blood flow through a patent ductus is small and takes place chiefly during systole. With the growth of the infant, the systemic blood pressure rises and the pulmonary arterial pressure falls, so that there is an appreciable blood flow through the ductus during both systole and diastole. The characteristic continuous murmur usually appears about the age of two or three years, though Taussig (1947) has observed a number of patients with a patent ductus and cardiac enlargement, who had not developed a typical murmur till the age of five or six years. Gilchrist (1945) pointed out that the characteristic murmur may disappear when congestive heart failure sets in, thus introducing a difficulty in diagnosis.

The absence of a Gibson murmur when pulmonary hypertension is present can be readily understood, for a rise in pressure within the pulmonary artery retards and eventually halts the entry of blood from the aorta. What does cause surprise, however, is the small number of patients so far reported in whom the characteristic ductus murmur had been noted before the diagnosis of pulmonary hypertension. Single instances of such disappearance of the Gibson murmur have been reported by Campbell and Hudson (1952), Burchell et al. (1953), Lukas et al. (1954), Harris (1955), and Whitaker et al. (1955). So far we have not met with an example of this, and we think there is a need to exercise caution in pronouncing on the presence of a Gibson murmur in this dual lesion since it may be closely simulated by the systolic and diastolic murmurs of pulmonary hypertension with pulmonary regurgitation. The rarity with which the disappearance of a Gibson murmur has been observed, before ligation of the ductus became common practice, suggests that pulmonary hypertension develops often at an early age in patients with a patent ductus.

The Electrocardiogram. In uncomplicated patent ductus arteriosus this is either normal or shows left ventricular preponderance. In the presence of pulmonary hypertension the tracing is dominated by the signs of right ventricular enlargement, though it may also show evidence of left ventricular enlargement (Fig. 6).

Radiology. The heart is only moderately enlarged as a rule, but the pulmonary trunk and its main branches may be considerably dilated and show exaggerated pulsation. The periphery of the lung fields tends to be abnormally translucent (Fig. 10 and 11).

Other Investigations. Reversal of the shunt may be diagnosed if the oxygen saturation of blood from the femoral artery is less than that from the brachial artery. Catheterization is of value in establishing the diagnosis of a patent ductus in the presence of pulmonary hypertension, for it is usually possible to pass the catheter through the ductus into the aorta. In this way not only may the anatomical diagnosis be confirmed, but the pressure gradient across the ductus and the pulmonary vascular resistance can be determined. Should it prove impossible to enter the ductus, this may be detected when there is still a left-to-right shunt, by finding a higher oxygen saturation in the pulmonary artery than in the right ventricle, although this is also found in other aorto-pulmonary communications.

Treatment. Surgical treatment of uncomplicated patent ductus arteriosus is an established procedure with a very low mortality (Gross, 1952; Neill and Mounsey, 1957). The success attendant 


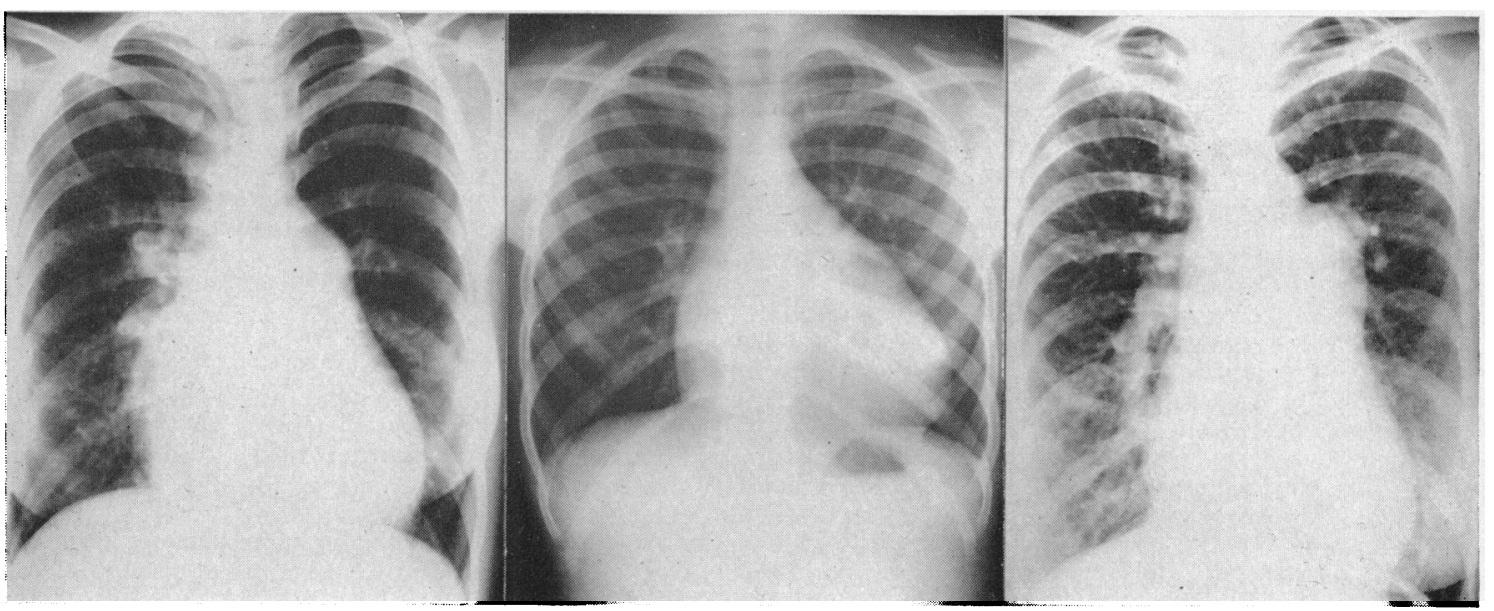

Fig. 10.-Patent Ductus Arteriosus and Pulmonary Hypertension. Considerable enlargement of RA, RV, and of PA and its primary branches. Periphery of lung fields clear. Case 7.
Fig. 11.-Patent Ductus Arteriosus and Pulmonary Hypertension. Enlargement of RA and of main PA, but not of its primary branches. $L V$ prominent from displacement by enlarged RV. Periphery of lung fields clear. Case 10 .
Fig. 12.-Persistent Truncus Arteriosus and Pulmonary Hypertension. Slight enlargement of RA and greater enlargement of RV. Left and right PA greatly dilated; their branches are visible as far as the periphery. Case 11.

on surgical treatment of a ductus associated with pulmonary hypertension inevitably depends on the ability of this procedure to reverse or retard the obstructive changes within the lesser pulmonary arteries and arterioles. Campbell (1955) stated that on the existing evidence it was unwise to assume that pulmonary hypertension was irreversible in any child, but that where the pressure had risen in infancy and the blood flow had been balanced or reversed, the surgical procedure was unlikely to reduce the high pressure because of the high arteriolar resistance and extensive structural changes in the pulmonary arterioles. Ellis et al. (1956) reviewed the progress following duct ligature of 30 cases in whom the pulmonary systolic pressure exceeded $60 \mathrm{~mm}$. Hg. The mortality rate for the whole group was 18 per cent, and in those in whom a right-to-left shunt was present it was 56 per cent. They concluded that surgical closure of a ductus was hazardous when the shunt was predominantly from right to left or if, following temporary occlusion of the duct at the time of the operation, the pressure rose in the pulmonary artery and fell in the aorta. Anderson et al. (1956) who reviewed 45 reported cases of patent ductus with reversal of flow found that only four of them had a good result from surgical treatment and each of these probably had bi-directional shunts. Crafoord (1951) pointed out that the surgical risk was greater in cases with pulmonary hypertension even if the shunt was not reversed. Having regard to the nature and extent of the arterial changes that are present we believe that the ductus should not be ligated when pulmonary hypertension, as defined here, complicates patent ductus arteriosus.

\section{Pulmonary Hypertension in Defects of the Aortic Septum Case Report}

Case 11. D. B., a single woman, aged 35, was first seen at the age of 11 when she had slight cyanosis and a diastolic murmur down the left border of the sternum. She led a sheltered life, and complained of no symptoms until the age of 34, when she attended hospital complaining of palpitation, dyspnœa on effort, and a single small hæmoptysis.

Examination. Cyanosis, but no clubbing of fingers. Pulse irregular from frequent extrasystoles, but otherwise normal. BP, 120/75. Jugular venous pulse normal. Right ventricular systolic lift. Pulmonary valve closure shook the chest. Short and very coarse systolic murmur in pulmonary area, but without a thrill. Second sound split, with a very loud pulmonary element, and followed by Graham Steell murmur. Hb, 118; WBC, 10, 250. 
Radiology. Slight enlargement of RA and greater of RV. Pulmonary trunk and left branch greatly dilated, but not abnormally pulsatile. Right PA prominent. Aorta somewhat dilated and more pulsatile than usual. Lung fields clear.

$E C$. Sinus rhythm; no extrasystoles recorded. S wave small in I and absent in leads CR1 and CR7. Tall R in same three leads. T inverted in CR1, CR2, and CR3 and very low in lead I. P wave moderately tall in CR1.

Cardiac Catheterization. PA mean pressure $83 \mathrm{~mm}$. Hg. Arterialization of blood in PA confirmed the presence of a communication between aorta and PA.

Course. She was considered to be a case of pulmonary hypertension in patent ductus arteriosus although the diagnosis of an aorto-pulmonary fistula was also entertained. A gross aortic septal defect was discovered at operation. An attempt was made to repair it, but the patient died on the operating table.

Necropsy. Customary changes of heart failure in viscera. No thrombosis in heart or in systemic veins.

Heart. Wt $468 \mathrm{~g}$. Great hypertrophy of RV $(1.5 \mathrm{~cm}$. thick) and slight of LV $(1.5 \mathrm{~cm}$. thick). Dilatation of RA and LA. Valves normal. No cardiac septal defects. Coronary arteries arising normally from aortic sinuses.

Lungs. Pulmonary trunk and aorta were joined to form a single grossly dilated vessel immediately on leaving heart and as far as bifurcation of PA. Wall of vascular swelling very thin. Both PAs greatly dilated. Right PA leaving conjoined aortic and pulmonary trunk posteriorly, and left PA turning immediately to left. Pulmonary arteriography showed right pulmonary artery and its segmental branches to be moderately dilated. Lobular arteries ended blindly with absence of their finest branches, and the presence of a dense network of tortuous anastomotic channels. Numerous areas of opaque material indicating infarcts.

Microscopy. Flecks of atheroma in elastic arteries. Muscular arteries, larger than $0.4 \mathrm{~mm}$. in diameter, normal, but great majority of smaller ones narrowed or occluded by intimal elastoid proliferation. Hypoplasia and often aplasia of media in many of these vessels. Similar intimal elastoid proliferation occluding many arterioles while others were in process of disintegration. Collateral channels abundant near obstructed muscular arteries, and many showed either thrombosis or intimal proliferation. Venules showed moderate endothelial thickening. Bronchial arteries prolific. Numerous pulmonary infarcts.

\section{Incidence}

Defects of the aortic septum appear in three forms, all of which are uncommon. The first is the serious defect, of which our case is an example, where the aorta and pulmonary trunk form a common arterial trunk (persistent truncus). In the second variety the fistula connects the aorta with the right ventricle or sometimes with the right atrium. The third is the rare condition where the right aortic sinus opens into the pulmonary trunk: the communication in this instance is usually small and measures about $1 \mathrm{~cm}$. in diameter (Dadds and Hoyle, 1949).

There were 21 cases of common arterial trunk in Abbott's series; in 18 where sex was noted 11 were male and 7 female. One survived to 25 years of age, but the mean age at death was only 4 years.

It is not possible to tell the incidence of pulmonary hypertension in the reported cases of common arterial trunk because the electrocardiogram, if recorded, has been an inadequate tracing for a firm opinion to be given on the presence of right heart preponderance, and the pulmonary arterial pressure has seldom been available. In Abbott's series two-thirds of the cases had right ventricular hypertrophy, and in the patient reported by Bain and Parkinson (1943), which closely resembled ours, the wall of the right ventricle was $1.0 \mathrm{~cm}$. thick.

With an experience limited to one case of a persistent truncus and pulmonary hypertension we are disinclined to speak of special clinical features that help in the diagnosis of the conjoined lesion, except that the electrocardiogram may show evidence of biventricular enlargement, and cardioscopy may show much pulsation and prominence in the customary position of the ascending aorta as well as in the pulmonary artery (Fig. 12).

Surgical closure of an aorto-pulmonary fistula is possible, although unwise in the presence of pulmonary hypertension, but such treatment is not yet possible in the case of a persistent truncus.

\section{Pathology}

The findings at necropsy have been given in detail under the separate case reports. Here we describe the pathological features relating to the added pulmonary hypertension.

Apart from the significant congenital fistulae, there were other congenital anomalies in 8 of our 11 cases. These included a strawberry nævus of the cheek in Case 3, a hypoplastic aorta in Case 5, a small atrial septal defect in Case 6, a small valvular patency of the foramen ovale in Cases 4 and 9, fused aortic cusps in Case 8, fenestration of the aortic cusps in Case 4, marked kyphoscoliosis in 


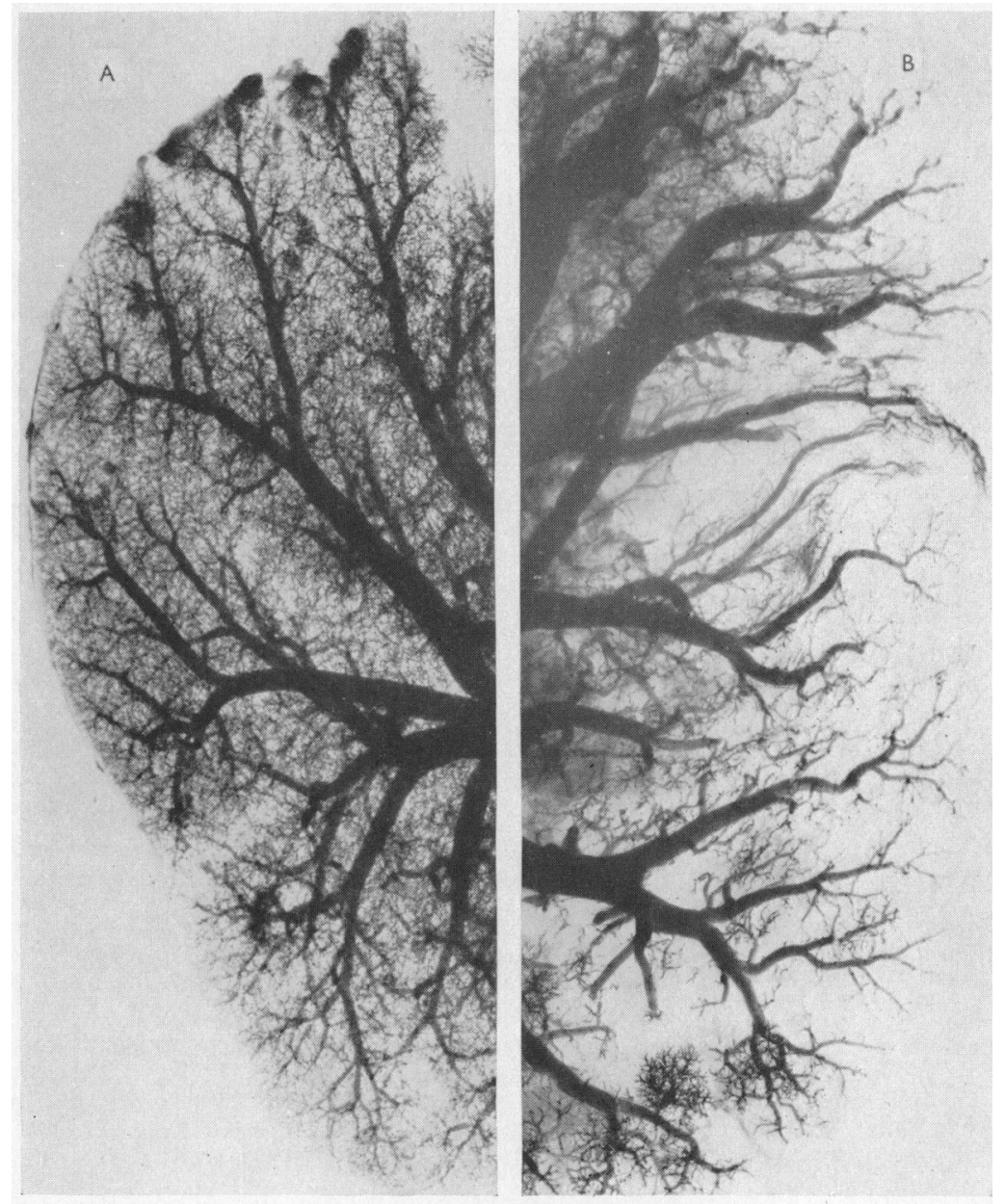

FIG. 13.-Pulmonary Arteriogram. (A) is from a patient with uncomplicated atrial septal defect. The defect was so great that the atria formed virtually a single chamber. (B) is from Case 1 with plumonary hypertension complicating atrial septal defect. The segmental arteries are enormously dilated. Many of the lobular arteries end abruptly, and the finest branches are lost throughout most of the lung, but in some areas the peripheral pattern is normal.

Case 10, and Madelung's deformity, with absence of the left uterine cornu and Fallopian tube and displacement of the left kidney to the right side in Case 7.

The Heart. This was always heavier than normal. The right ventricle was invariably hyper. trophied and was usually moderately dilated. Its thickness varied between 7 and $15 \mathrm{~mm}$. with a mean of $11 \mathrm{~mm}$. The left ventricle was hypertrophied only in the cases with ventricular septal defect. The right atrium was only slightly dilated and hypertrophied, except in the cases with atrial septal defect and in one case with patent ductus arteriosus where both dilatation and hypertrophy were greater. Intracardiac thrombosis was present only once.

The Lungs. The lung parenchyma was normal except for areas of infarction which appeared in 5 of the 11 cases. The pulmonary trunk was always dilated, and so as a rule were the main segmental branches; this change was particularly noticeable in patients with atrial septal defect. Mod- 

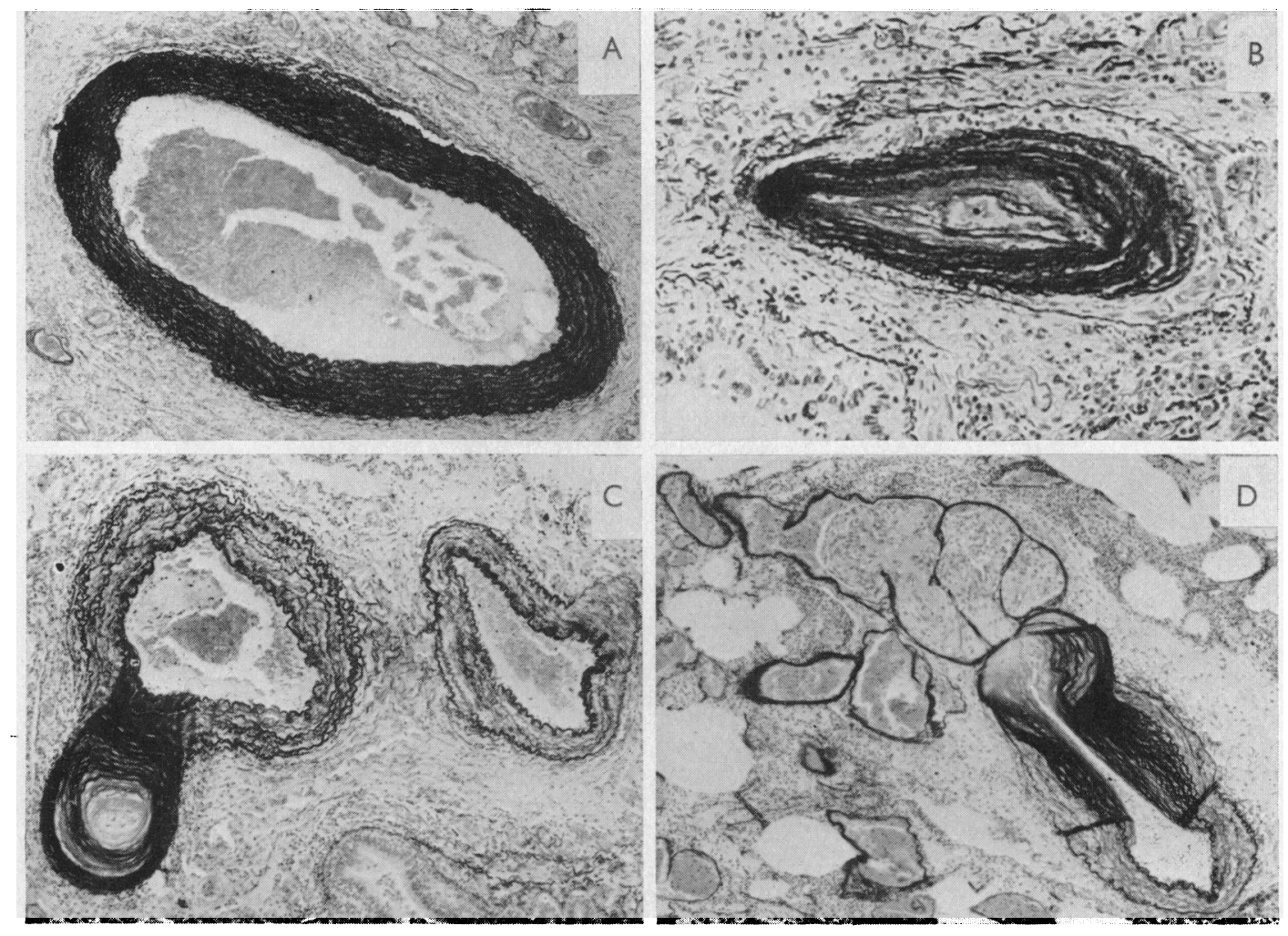

FIG. 14.-Patent Ductus Arteriosus and Pulmonary Hypertension. (A) Elastic reduplication in media of small elastic artery $(1 \cdot 1 \mathrm{~mm}$. diam.) probably indicating arterial contracture. $\times 20$. (B) Elastoid intimal proliferation which almost occludes muscular artery $(0.14 \mathrm{~mm}$. diam.) whose media is greatly thinned on its inferior aspect. $\times 152$. (C) Elastoid proliferation within branch or collateral channel arising from contracted elastic artery $(0.56 \mathrm{~mm}$. diam.). $\times 63$. (D) Collateral channels filled for most part by organizing thrombus. $\times 41$. Case 8 .

erate atherosclerosis was usually present in these vessels, and in one case of patent ductus arteriosus there was severe intimal calcification extending from the pulmonary trunk as far as the segmental arteries. In two cases the right or the left pulmonary artery was occluded by thrombus, and in four others thrombus had either partly or completely closed a segmental artery. The bronchial arteries in their extra-pulmonary course were normal.

Pulmonary Arteriography. Although we hold that this investigation should have pride of place in the post-mortem examination of any case of pulmonary hypertension, the opportunity was only afforded us in three of our cases, and in one control case with a large atrial septal defect without pulmonary hypertension. In the control case the pulmonary trunk and its branches were moderately dilated, and the pulmonary vascular pattern was normal (Fig. 13A). In the cases of pulmonary hypertension the appearances were similar to those found in pulmonary hypertension associated with mitral stenosis or occurring alone, and indicated obstruction within the lesser pulmonary arteries and arterioles. The obstructed arteries were approximately 0.5 to $2.0 \mathrm{~mm}$. diameter in one case, $0.2 \mathrm{~mm}$. in the second, and $0.4 \mathrm{~mm}$. in the third case. Such vessels were seen to end blindly (Fig. 13B) and in many places the normal arteriolar pattern was replaced by tortuous collateral channels. Infarcted areas were present in the control case and in two of the cases with pulmonary hypertension. 
Histological Findings. The pulmonary arteries in uncomplicated atrial septal defect, ventricular septal defect, and patent ductus arteriosus show only patchy intimal thickening similar to that in control subjects (Welch and Kinney, 1948; Edwards, 1955). The changes found on microscopical examination of the lungs in our 11 cases with pulmonary hypertension were uniform, nor did they differ in any important respect from those found in solitary pulmonary hypertension (Evans et al., 1957).

In 9 of the 11 cases there was widespread obstruction in the muscular $(0.1$ to $1.0 \mathrm{~mm}$. diameter, and small elastic arteries slightly exceeding $1.0 \mathrm{~mm}$. diameter. In the remaining two the changes were less noticeable although in both of these only a limited number of sections were available. In four cases the main obstruction was in the small elastic and the large muscular arteries; in four the brunt fell on the medium-sized muscular arteries, and in one on the small muscular arteries. In the elastic arteries the tissue that blocked the vessels often had the appearance of organizing thrombus. In the muscular arteries the tissue was usually fibrotic and seemed reactive and reparative rather than passive, and we have described this change as intimal proliferation. In seven of our cases this newer tissue contained an abundance of elastic fibres and we have referred to this as elastoid intimal proliferation (Fig. 14). Such reaction was commoner in pulmonary hypertension associated with congenital shunts than in that associated with mitral stenosis or occurring alone.

The intimal proliferation usually overlay segments of medial hypoplasia, while sometimes this weakness of the arterial wall amounted to aplasia, the vessel showing only a single elastic layer, and thus resembling an arteriole except for its larger size (Fig. 15, 16, 17, and 18).

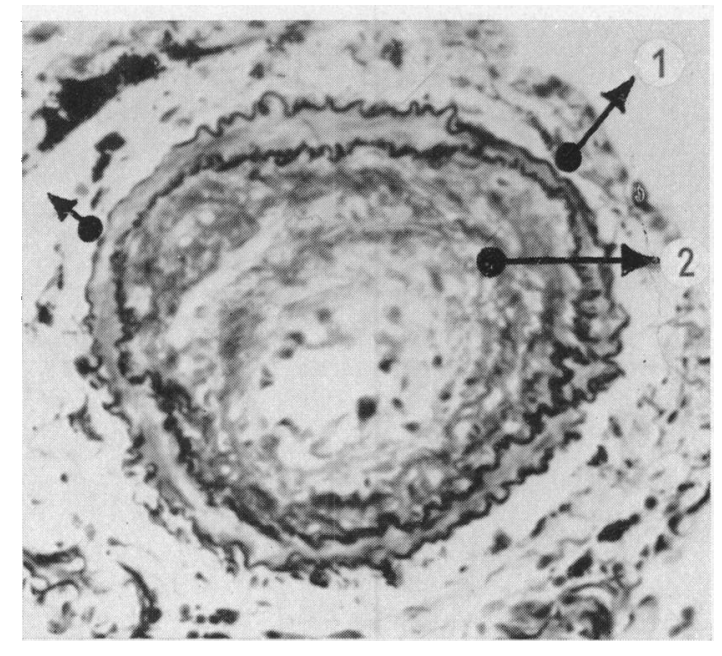

FIG. 15.-Atrial Septal Defect and Pulmonary Hypertension. Hypoplasia (1) of media of muscular artery $(0.16 \mathrm{~mm}$. diam.). Intimal proliferation (2) almost occluding the lumen. $\times 300$. Case 1 .

Collateral channels, similar to those described by Brewer (1955), were abundant in seven cases in which the main obstruction was in the medium-sized or larger muscular arteries; they were situated near the site of obstruction. When empty, such channels appeared as spaces surrounded by a thin layer of endothelium supported by an elastic membrane. Frequently, however, they were filled with organizing tissue which sometimes showed canalization (Fig. 14D, 16C, and 16D).

Only a limited number of sections were available for histological examination in the two cases in which intimal proliferation was inconspicuous. The most striking abnormality in these was the presence of a distinct muscular coat in vessels of arteriolar size (less than $0.1 \mathrm{~mm}$. diameter), and 

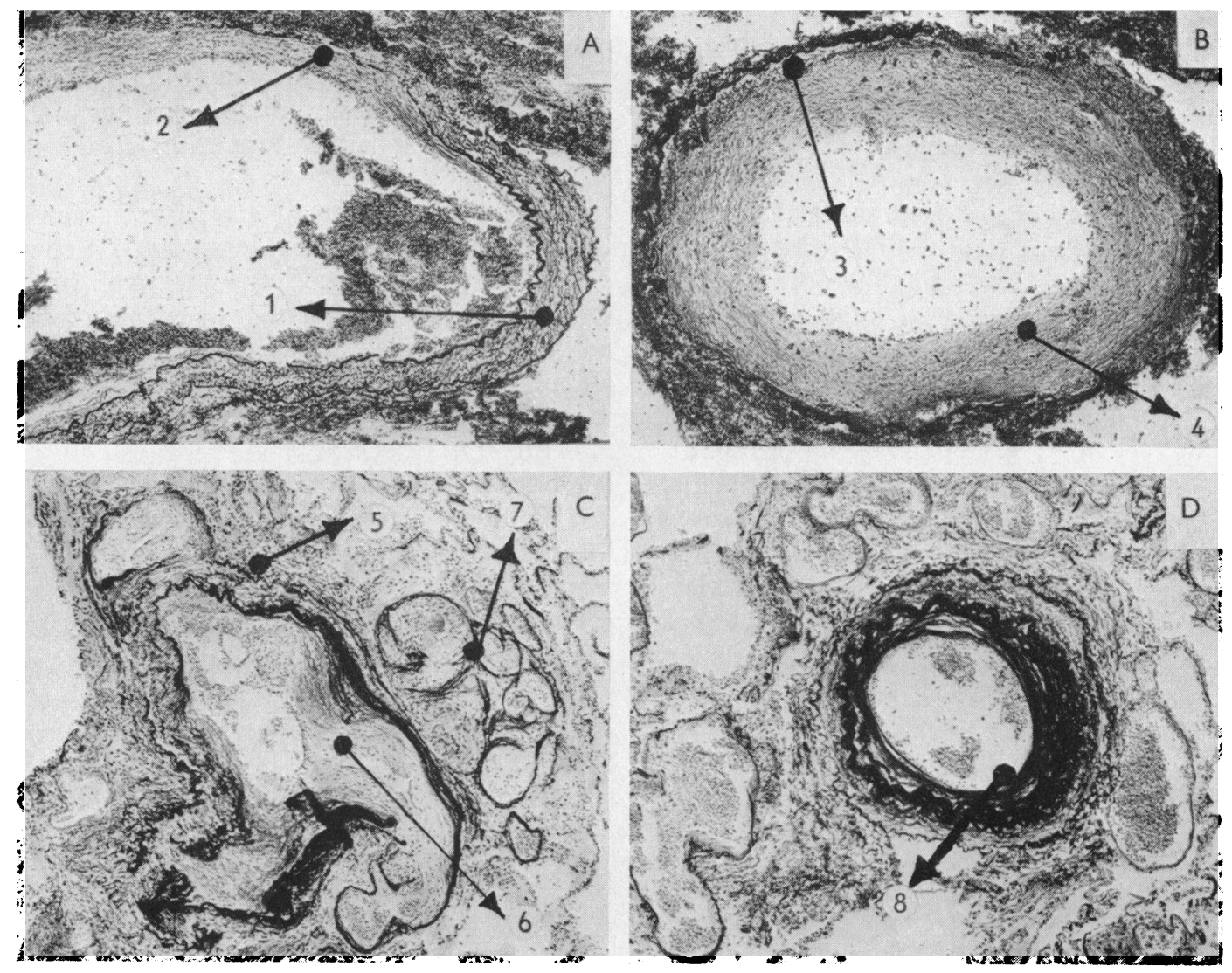

FIG. 16.-Ventricular Septal Defect and Pulmonary Hypertension. (A) Muscular artery (0.86 mm. wide) showing normal media at (1), and aplasia with adjacent intimal proliferation at (2). (B) Aplasia (3) of entire circumference of muscular artery $(0.9 \mathrm{~mm}$. diam.) with intimal proliferation (4) which greatly narrows lumen. (C) Collateral channels (6 and 7), the majority of which are filled with organizing thrombus, arising from muscular artery (5) greatly narrowed by intimal proliferation. $\times 47$. (D) Elastoid intimal proliferation (8) within muscular artery $(0.65 \mathrm{~mm}$. diam.) whose media shows hypoplasia. $\quad \times 47$. Case 6 .

apparent medial hypertrophy in the larger arteries (Fig. 19). These changes were also present in 6 of the 9 cases with prominent intimal proliferation. Similar changes were found in our cases of mitral stenosis with pulmonary hypertension (Evans and Short, 1957). Arteriography has shown that these vessels are relatively indistensible and we have described this diffuse intractable narrowing as arterial contracture.

\section{PATHOGENESIS}

Any theory that purports to explain the development of pulmonary hypertension in the presence of cardiac or aorto-pulmonary shunts must account for the severe and widespread arterial obstruction, which is invariably found at necropsy.

These arterial lesions are not merely terminal. This is evident both from the histological appearances, and from the fact that similar lesions are found in lung sections taken at operation (Heath and Whitaker, 1955). This explains why the pressure in the pulmonary artery does not fall when the shunt is arrested, as in the case of ligation of the ductus (Shephard, 1954). 

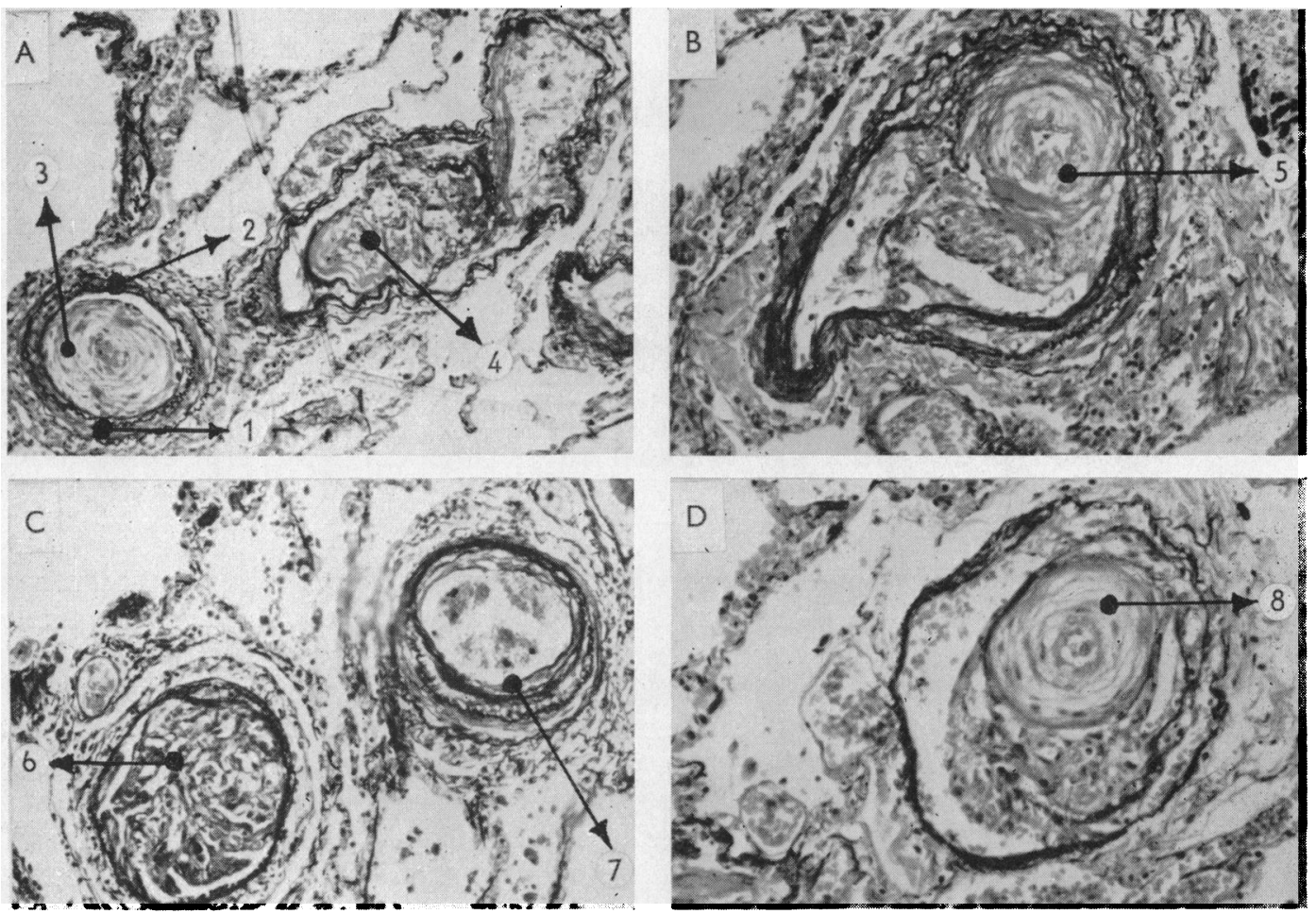

Fig. 17.-Atrial Septal Defect and Pulmonary Hypertension. (A) Hypoplasia (1) (2) of media of muscular artery $(0.19 \mathrm{~mm}$. diam.) containing organizing thrombus (3). Similar thrombus (4) in a collateral vessel. $\times 95$. (B) Intimal proliferation and thrombosis (5) in muscular artery $(0.23 \mathrm{~mm}$. diam.) showing medial hypoplasia adjacent to it. (C) Thrombus (6) in a collateral vessel and elastoid intimal proliferation (7) in a muscular artery $(0.17 \mathrm{~mm}$. diam.) part of whose wall shows aplasia. $\times 125$. (D) Re-canalization (8) of muscular artery $(0.20 \mathrm{~mm}$. diam.) which shows aplasia and hypoplasia of its media. $\times 175$. Case 2 .
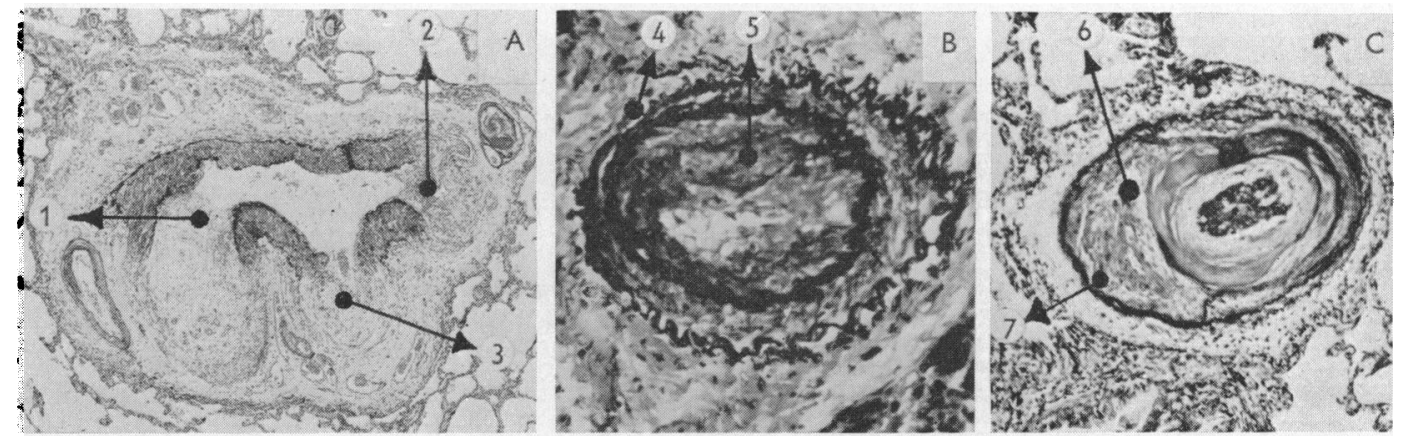

FIG. 18.-Patent Ductus Arteriosus and Pulmonary Hypertension. (A) Breaches (1, 2, and 3) in the media of a muscular artery $(0.45 \mathrm{~mm}$. wide) filled with organizing thrombus. $\times 26$. (B) Hypoplasia of media (4) of muscular artery $(0.25 \mathrm{~mm}$. diam.) with intimal proliferation (5) which almost occludes its lumen. $\times 125$. (C) Similar proliferation (6) and thrombosis within muscular artery $(0.30 \mathrm{~mm}$. diam.) which shows segmental medial aplasia (7). $\times 80$. Case 7 . 

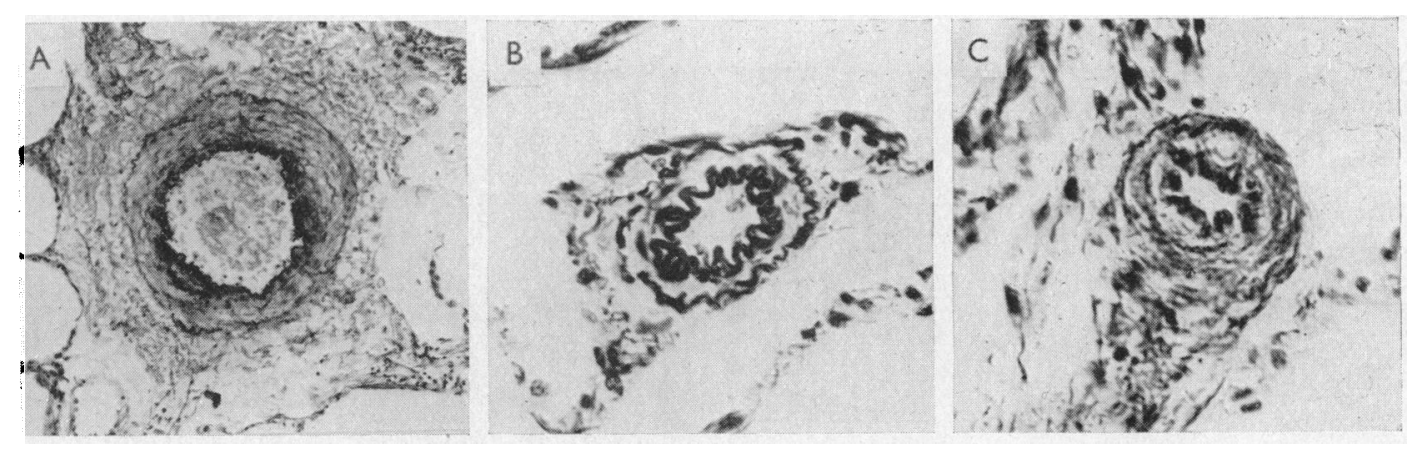

FIG. 19.--Ventricular Septal Defect and Pulmonary Hypertension. (A) Apparent hypertrophy of muscular artery $(0.30 \mathrm{~mm}$. diam.), probably indicating arterial contracture. $\times 80$. (B) Contracture of muscular artery $(40 \mu$ diam.) with deep crenation of the internal elastic lamina. $\times 400$. (C) Intimal proliferation, with pallisading effect within arteriole $(40 \mu$ diam.) which is the same size as muscular artery in $\mathrm{B}$. $\times 400$. Case 5 .

Pulmonary embolism and thrombosis are important aggravating factors once pulmonary hypertension has developed (Dexter, 1956), but there is no evidence that they initiate the hypertension. Pulmonary arteritis has occasionally been described in cases of pulmonary hypertension (Old and Russell, 1950), but as a rule there is no histological evidence of inflammation or scarring.

It is widely held that the development of pulmonary hypertension is related to the magnitude of the left-to-right shunt (Swan et al., 1954). It has been said that hypertension is commoner in the presence of a large ventricular septal defect or ductus than a small one. Nevertheless, by no means all patients with a large ductus develop hypertension. Campbell (1955) observed that some of the patients with large shunts reached a good age and developed left ventricular failure without evidence of pulmonary hypertension. We have not found any correlation between the size of the shunt and the presence or absence of pulmonary hypertension. The diameters of the duct in our four cases for instance were $0.9,1 \cdot 0,1 \cdot 5$, and $1.0 \mathrm{~cm}$. respectively. In 47 cases of patent ductus without pulmonary hypertension treated surgically at the London Hospital in whom a measure of the ductus was taken, 25 were classified as small $(0.25$ to $0.75 \mathrm{~cm}$. diam.), 10 as medium $(0.75$ to $1.0 \mathrm{~cm}$. diam. $)$ and 12 as large (over $1.0 \mathrm{~cm}$. diam.) (Mounsey, 1957). Furthermore, pulmonary hypertension may be found in association with a small ductus (Limon-Lason et al., 1950). We do not, therefore, subscribe to the view that an increase in the pulmonary blood flow is the cause of pulmonary hypertension, although it can hasten its progression in the presence of another ætiological factor.

Such considerations suggest that there is a congenital predisposition to pulmonary hypertension in certain patients. Edwards (1950) has pointed to the similarity between the apparently hypertrophied arteries of the patient with hypertension and the thick-walled arteries of the fœtus, and has postulated that in patients who will develop hypertension, the fœtal state persists into childhood. Edwards (1957) believes that the obliterative lesions develop later as a specific effect of severe chronic hypertension. The main objection to Edwards' theory is that apparently similar thick-walled arteries are found in pulmonary hypertension associated with mitral stenosis, and it is very difficult to believe that the arterial abnormality here is an independent condition present from birth. Furthermore, there is some evidence that in cases of congenital heart disease destined to develop hypertension the normal evolution of the pulmonary arteries takes place in the early months of post-natal life. Thus, Dammann and Ferencz (1956) have shown that the pulmonary vascular resistance in cases with a large ventricular septal defect tends to fall toward normal in the early post-natal months. Brotmacher and Campbell (1958) also imply that the resistance is not as a rule high in infancy, but rises gradually with the passage of years.

The evidence obtained by correlating post-mortem arteriography with histology indicates that the apparent medial hypertrophy is an expression of persistent, diffuse, organic constriction, which 
we have termed arterial contracture. The manner in which arterial contracture develops is not known. Bayliss (1902) showed that the muscular coat of arteries, like smooth muscle in other situations, reacts to a stretching force by contraction. A moderate rise in pressure from any cause, e.g. increased blood flow, induces in susceptible subjects abnormal vasoconstriction (Wood, 1952), and this, if it persists, leads ultimately to persistent shortening of the muscular fibres and elastic laminæ (Short, 1957). If it is assumed that the inherent responsiveness of the arteries to a raised pressure is not universal, but varies from one subject to another, it may explain the development of pulmonary hypertension. Occlusive changes would then be regarded as a late development leading to reversal of the shunt, as Dammann and Ferencz (1956) and Edwards (1957) have suggested.

That inherent weakness of the media of the lesser pulmonary arteries is responsible for the complication of pulmonary hypertension in congenital heart disease was a view first advanced by Evans (1951) who was so impressed with its association with congenital fistulæ, that he referred to it as congenital pulmonary hypertension. That such medial deficiencies played an ætiological role in pulmonary hypertension was first postulated by Gilmour and Evans (1946) in a case of so-called primary pulmonary hypertension. They believed that in this condition the intimal proliferation occurred over some of those deficiencies, which numbered several thousands, during attacks of mild and transient hypertension as might have been produced by coughing, and that subsequently the resulting arterial stenosis or occlusion led to persistent hypertension.

In the case of cardiac and aorto-pulmonary shunts the pressure in the pulmonary artery rises. If this takes place in the presence of congenital hypoplasia or aplasia in the media of the lesser pulmonary arteries, it is postulated that intimal proliferation results, leading to progressive obstruction of the arteries and severe persistent hypertension.

Whatever the nature of the congenital anomaly responsible for the development of pulmonary hypertension there are certain circumstances that inevitably aggravate the condition. Pulmonary embolism and thrombosis have already been mentioned. Whittaker and Winton (1933) showed that an increase in corpuscular concentration above the normal leads to a considerable rise in viscosity and therefore to an increase in the vascular resistance. Again, the system of collateral channels which develops when large arteries are obstructed must be an inefficient substitute for the normal pathway. Moreover, their width and tortuosity make them very liable to thrombosis, and this event may actually precipitate the death of some of the patients.

\section{Summary AND CoNCLUSIONS}

The pulmonary vasculature was specially examined at necropsy in 11 patients in whom a congenital intracardiac or aorto-pulmonary communciation was complicated by pulmonary hypertension. The congenital anomaly was an atrial septal defect in three cases, a ventricular septal defect in three, a patent ductus arteriosus in four, and a common aorto-pulmonary trunk in one case.

We have adhered to the definition of pulmonary hypertension as a state of persistent elevation of the pulmonary arterial pressure sufficient to cause enlargement and ultimately failure of the right ventricle, and with characteristic clinical, electrocardiographic, and radiological signs. The diagnosis in our patients was made without recourse to pulmonary arterial catheterization.

The changes in the pulmonary arteries among our 11 cases were uniform, and did not depend on the position of the congenital communication. They differed in no important respect from those found in solitary pulmonary hypertension or in hypertension associated with mitral stenosis.

The pulmonary arteriogram showed great restriction of the peripheral arterial bed throughout the lung. Histological examination demonstrated widespread obstruction of arteries less than $2 \mathrm{~mm}$. in diameter by intimal proliferation in which thrombosis with subsequent organization played a part. The muscular arteries were particularly affected, and in them the intimal proliferation, usually in the form of an elastoid reaction, was associated with hypoplasia or even aplasia of the media. Near occluded arteries there were often large collateral channels, which were sometimes filled with 
organizing thrombus. Diffuse arterial contracture was frequently seen in the muscular arteries, which were often as small as $0.04 \mathrm{~mm}$. in diameter.

This investigation has established that vascular obstruction accounts for persistent pulmonary hypertension in congenital heart disease. In the circumstance, closure of the septal defect or ductus arteriosus cannot be curative.

The presence of such pulmonary vascular disease is not directly related either to the age of the patient or to the size of the congenital communication. We conclude that there resides in the pulmonary arteries an inherent predisposition to the development of arterial obstruction leading to pulmonary hypertension.

Although pulmonary hypertension has not been an uncommon clinical finding among our patients with congenital heart disease, the opportunity to examine 11 cases at necropsy could not have been given us except through the help of many colleagues. Professor Dorothy Russell has made available the material obtained at necropsy in eight of the cases. Cases 3, 5, 6, and 8 were one time under the care of Dr. Wallace Brigden, while Dr. Robert Benson supervised Case 6 during the last phase of his illness and supplied us with material obtained at necropsy. It was through the kindness of Dr. Frederic Jackson, Mr. George Mason, and Dr. B. E. Tomlinson that we were able to include Case 11 in the series. Dr. R. Hudson helped us with Case 2 which was under the care of Dr. Graham Hayward. Necropsy material was made available to us by Dr. T. V. Cooper in Case 4, and by Dr. L. W. B. Dobbin in Case 10. To these several colleagues we wish to express our great indebtedness for their help.

\section{REFERENCES}

Abbott, M. E. (1936). Atlas of Congenital Heart Disease. New York.

Anderson, R. C., Adams, P., and Varco, R. L. (1956). Pediatrics, 18, 410.

Bain, C. W. C., and Parkinson, J. (1943). Brit. Heart J., 5, 97.

Barber, J. M., Magidson, O., and Wood, P. (1950). Brit. Heart J., 12, 277.

Barclay, A. E., Franklin, K. J., and Prichard, M. L. (1944). The Foetal Circulation and Cardiovascular System and Changes they Undergo at Birth. Oxford.

Bayliss, W. M. (1902). J. Physiol., 28, 220.

Bedford, D. E. (1957). Personal communication.

- Sellors, T. H., Somerville, W., Belcher, J. R., and Besterman, E. M. M. (1957). Lancet, 1, 1255.

Brewer, D. B. (1955). J. Path. Bact., 70, 299.

Brotmacher, L., and Campbell, M. (1958). Brit. Heart J., 20, 97.

Brown, J. W., Heath, D., and Whitaker, W. (1955). Brit. Heart J., 17, 273.

Burchell, H. B., Swan, H. J. C., and Wood, E. H. (1953). Circulation, 8, 681.

Campbell, M. (1951). Brit. Heart J., 13, 438. (1955). Brit. Heart J., 17, 511 .

—_, and Hudson, R. (1951). Guy's Hosp. Rep., 100, 26.

- - (1952). Guy's Hosp. Rep., 101, 32.

, Neill, C., and Suzman, S. (1957). Brit. med. J., 1, 1375.

Cosh, J. A. (1957). Brit. Heart J., 19, 13.

Crafoord, C. (1951). Brit. med. J., 1, 946.

Dadds, J. H., and Hoyle, C. (1949). Brit. Heart J., 11, 390.

Dammann, J. F., and Ferencz, C. (1956). Amer. Heart J., 52, 210.

Dexter, L. (1956) Brit. Heart J., 18, 209.

DuShane, J. W., Kirklin, J. W., Patrick, R. T., Donald, D. E., Terry, H. R., Burchell, H. B., and Wood, E. H. (1956). J. Amer. med. Ass., 160, 950.

Edwards, J. E. (1950). Proc. Inst. Med., Chicago, 18, 134. (1955). In Cardiovascular Surgery. W. B. Saunders. (1957). Circulation, 15, 164.

Ellis, F. H., Kirklin, J. W., Callahan, J. A., and Wood, E. H. (1956). J. thorac. Surg., 31, 268.

Espino-Vela, J., and Mata, L. A. (1956). Amer. Heart J., 51, 284.

Evans, W. (1951). Proc. Roy. Soc. Med., 44, 600.

$\longrightarrow$, and Short, D. S. (1957). Brit. Heart J., 19, 457.

,,- and Bedford, D. E. (1957). Brit. Heart J., 19, 93.

Gilchrist, A. R. (1945). Brit. Heart J., 7, 1.

Gilmour, J. R., and Evans, W. (1946). J. Path. Bact., 58, 687,

Gross, R. E. (1952). Amer. J. Med., 12, 472.

Hamilton, W. F., Woodbury, R. A., and Woods, E. B. (1937). Amer. J. Physiol., 119, 206.

Harris, P. (1955). Brit. Heart J., 17, 85.

Heath, D., and Whitaker, W. (1955). J. Path. Bact., 70, 285.

Hultgren, H., Selzer, A., Purdy, A., Holman, E., and Gerbode, F. (1953). Circulation, 8, 15.

Lequime, J., Denolin, H., and Hanson, J. (1956). 2nd European Congress of Cardiology, Stockholm.

Limon-Lason, R., Bouchard, F., Rubio-Alvarez, V., Cahen, P., and Novelo, S. (1950). Arch. Inst. Cardiol. Mexico, $20,147$. 
Lukas, D. S., Araujo, J., and Steinberg, I. (1954). Amer. J. Med., 17, 298.

Mounsey, J. P. D. (1957). Personal communication.

Neill, C., and Mounsey, J. P. D. (1958). Brit. Heart J., 20, 61.

Old, J. W., and Russell, W. O. (1950). Amer. J. Path., 26, 789.

Pedersen, A., Davidsen, H. G., Fabricus, J., and Hansen, A. T. (1956). 2nd European Congress of Cardiology, Stockholm.

Selzer, A., and Laqueur, G. L. (1951). Arch. intern. Med., 87, 218.

Shephard, R. J. (1954). Brit. Heart J., 16, 361.

Short, D. S. (1957). Lancet, 2, 12.

Sones, F. M. (1956). J. thorac. Surg., 31, 283.

Swan, H. J. C., Zapata-Diaz, J., Burchell, H. B., and Wood, E. H. (1954). Amer. J. Med., 16, 12.

Taimont, F., Carouso, G., Mège, A., and Lenègre, J. (1952). Arch. Mal Couur, 45, 927.

Taussig, H. B. (1947). Congenital Malformations of the Heart. Commonwealth Fund, New York.

Wagner, J., and Graham, G. R. (1957). Brit. Heart J., 19, 318.

Walker, W. J., Mattingly, T. W., Pollock, B. E., Carmichael, D. B., Inmon, T. W., and Forrester, R. H. (1956). Amer. Heart J., 52, 547.

Welch, K. J., and Kinney, T. D. (1948). Amer. J. Path., 24, 729.

Whitaker, W., Heath, D., and Brown, J. W. (1955). Brit. Heart J., 17, 121

Whittaker, S. R. F., and Winton, F. R. (1933). J. Physiol., 78, 339.

Wood, P. (1952). Brit. med. Bull., 8, 348. (1956). Diseases of the Heart and Circulation. 2nd Edition. Eyre and Spottiswoode, London.

-_, Wilson, P. O., and Magidson, O. (1954). Brit. Heart J., 16, 387. 